\title{
UDC 347.21.3
}

SCOPUS CODE 3301

https://doi.org/10.36073/1512-0996-2021-3-152-167

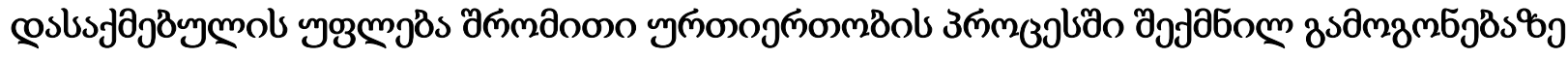

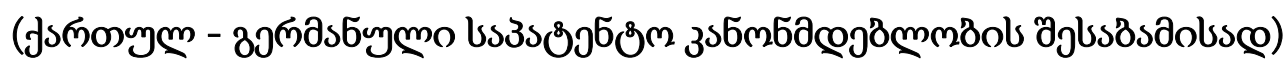

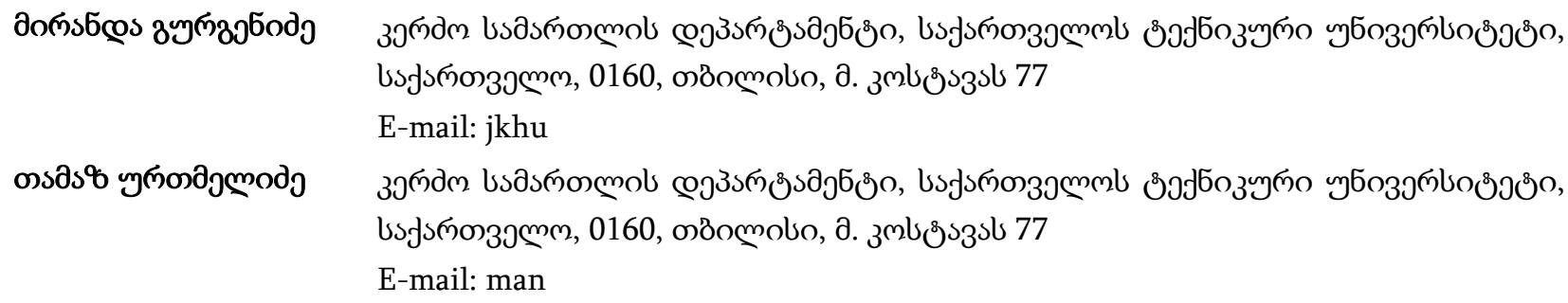

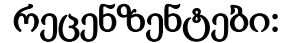

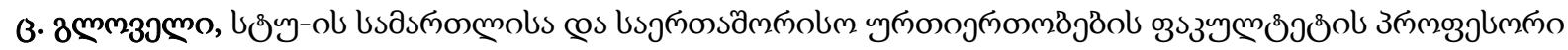
E-mail: gloveli99@mail.ru

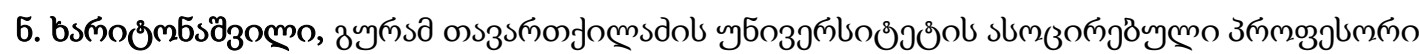

E-mail: nkharitonashvili@gmail.com

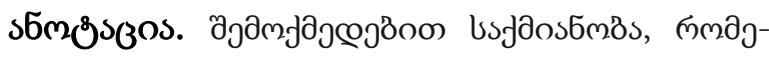

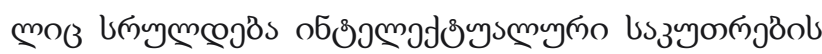

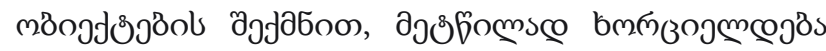

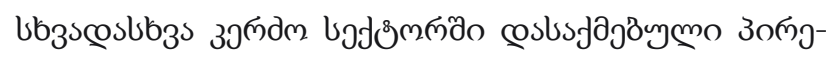

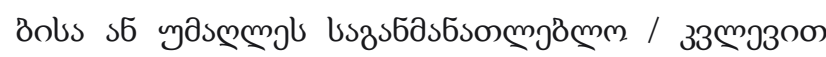

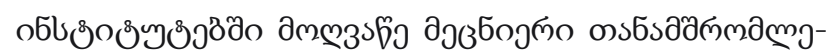
oob dogณ.

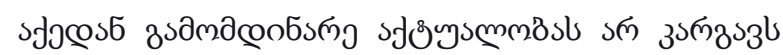

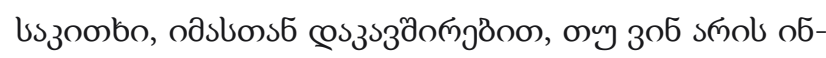

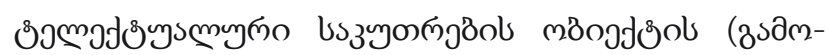

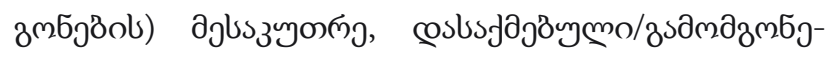

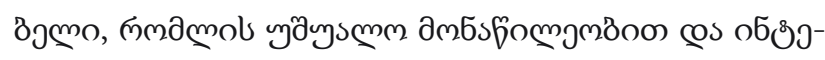

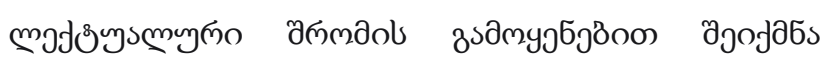

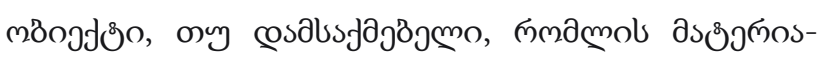

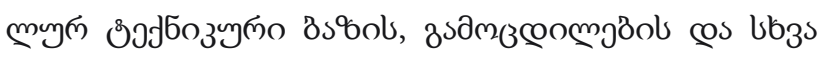

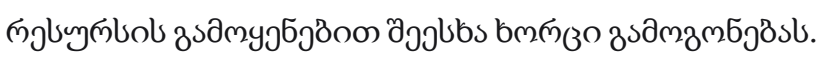

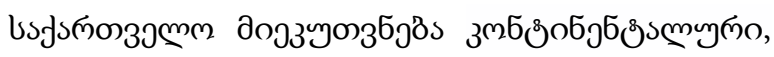

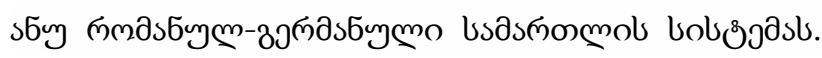

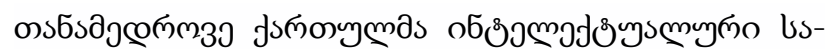

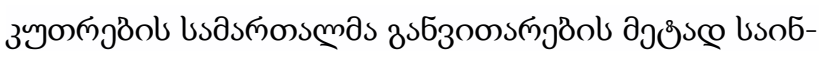

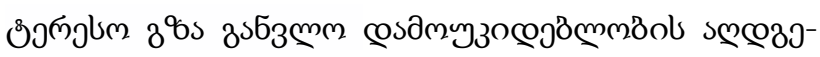




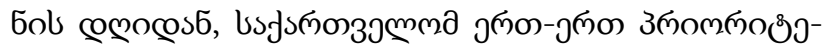

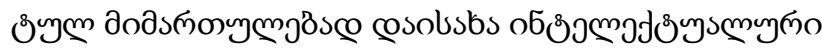

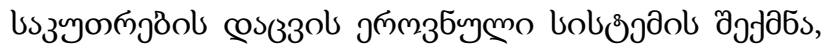

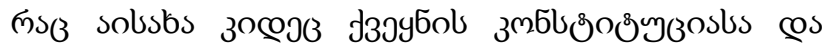

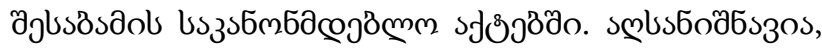

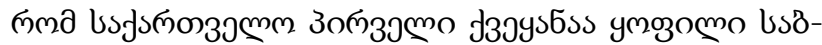

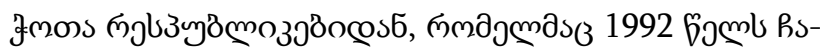

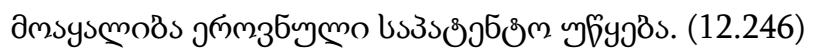

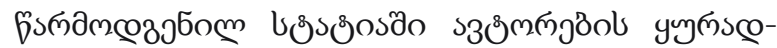

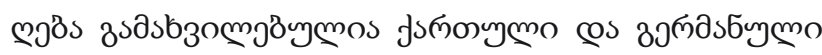

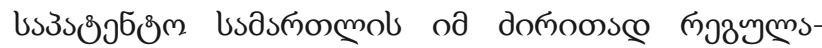

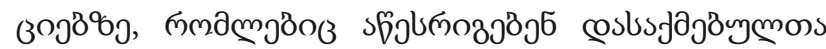

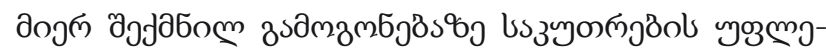

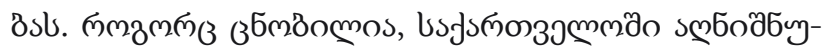

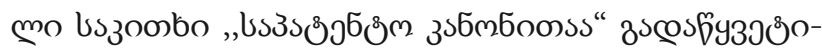

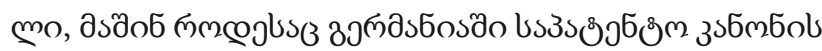

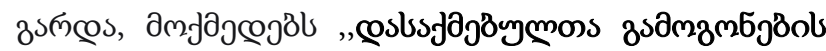
yjusbja" sjతిం.

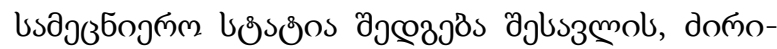

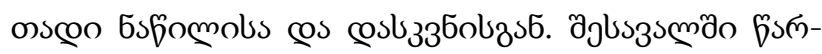

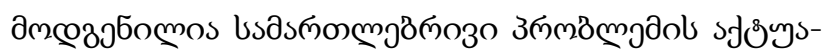

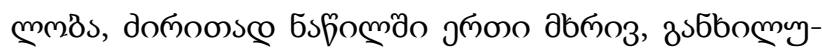

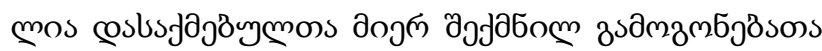

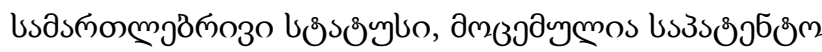

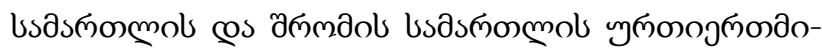

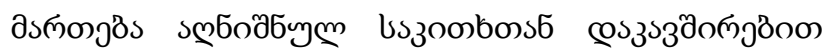

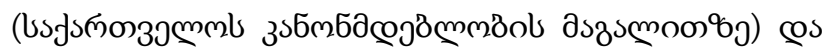

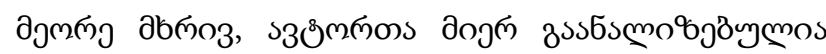

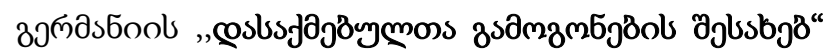

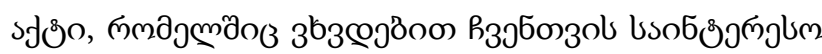

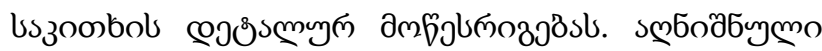

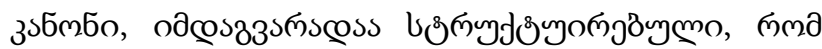

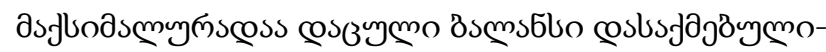

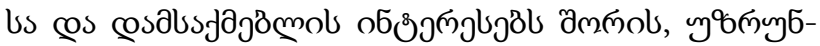

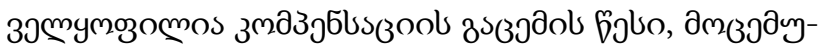

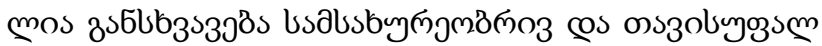

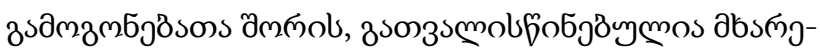

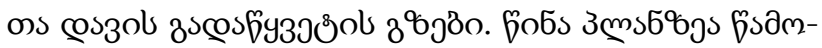

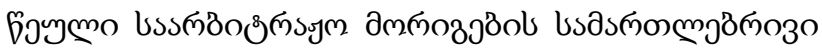

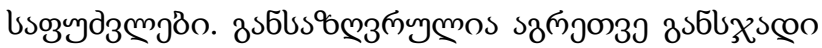

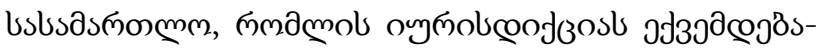

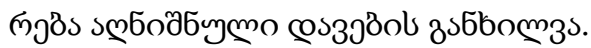

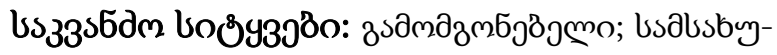

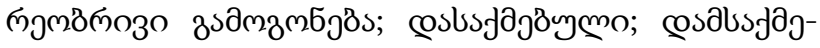

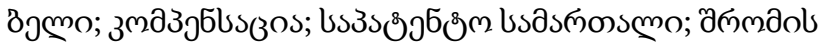
usasmossmo.

\section{gjuszsmo}

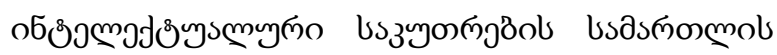

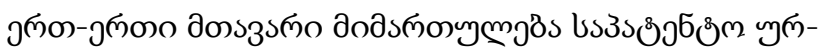

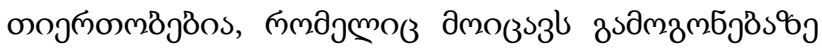

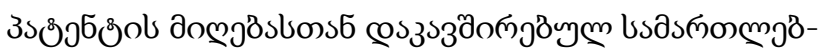

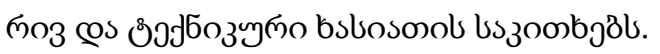

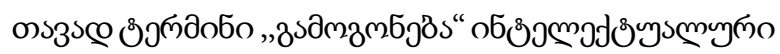

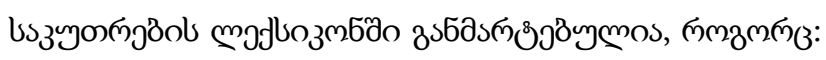

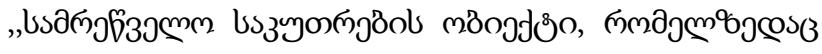

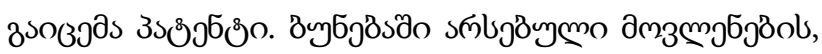

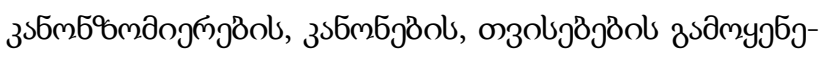

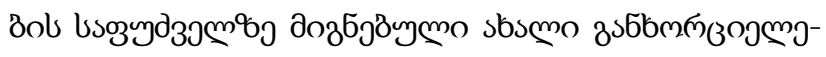

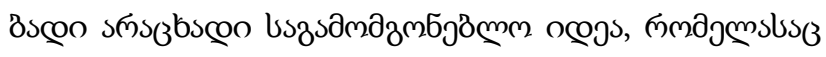

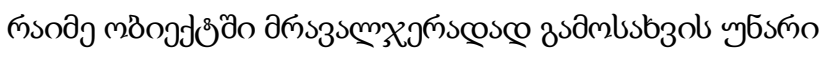

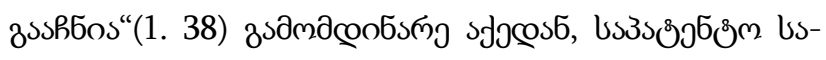

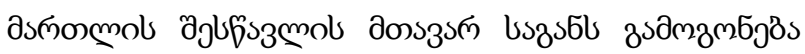

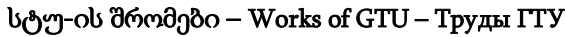




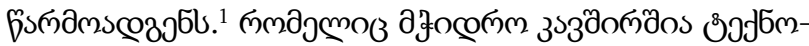

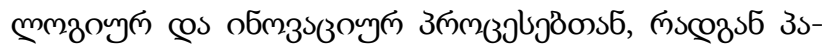

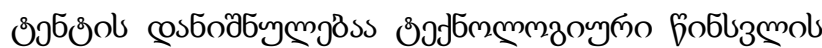

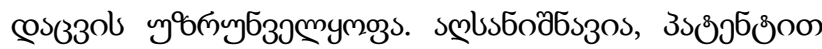

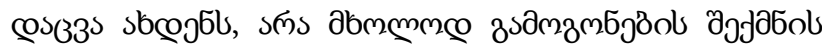

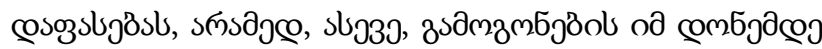

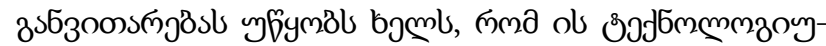

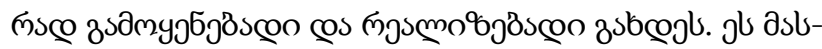

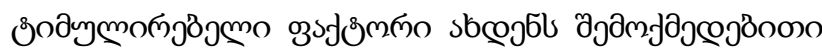

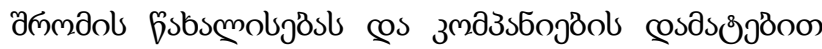

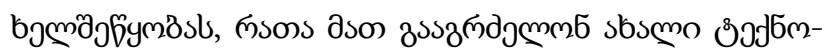

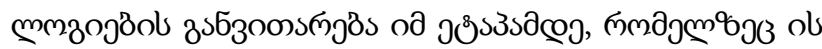

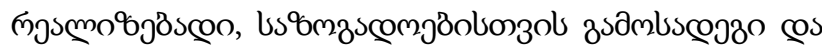

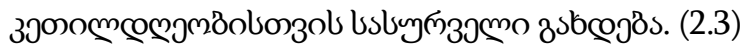

\section{donoonscoo 6sformo}

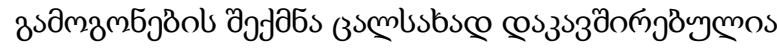

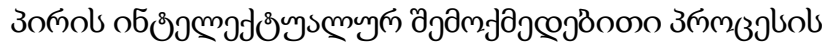

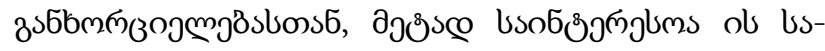

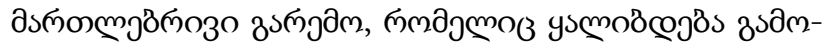

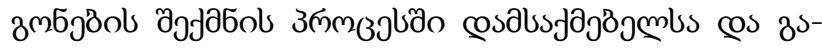

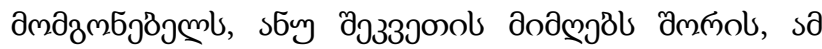

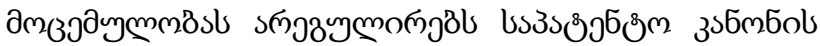

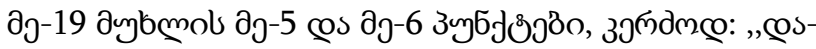

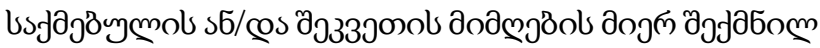

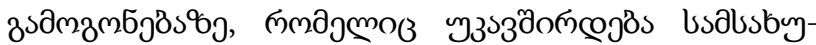

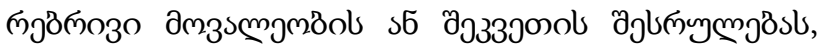

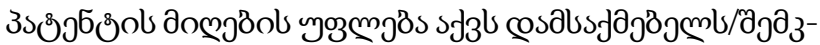

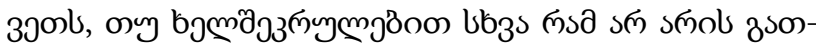

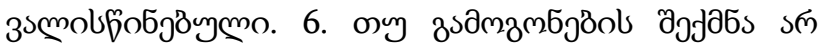

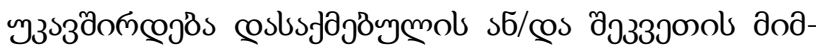

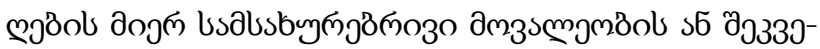

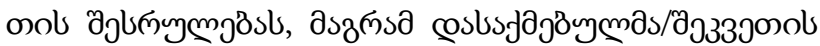

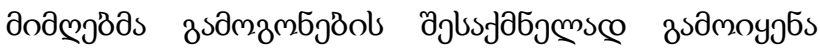

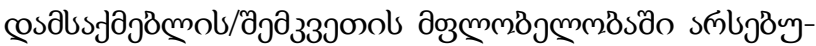

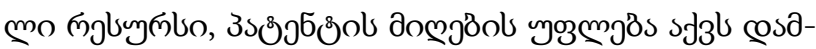

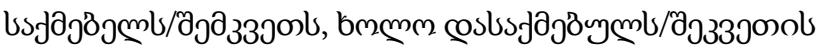

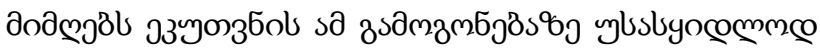

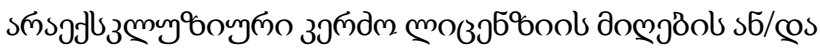

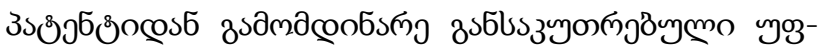

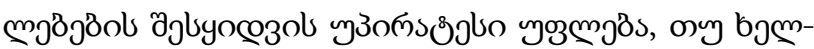

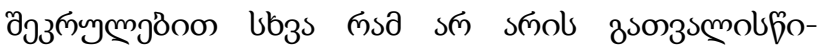

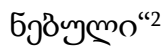

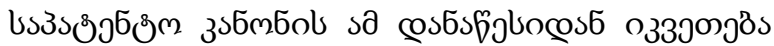

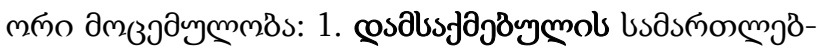

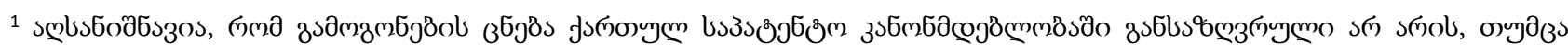

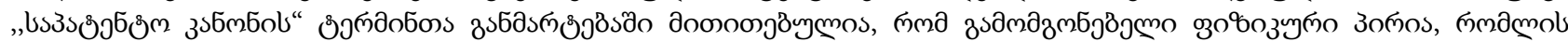

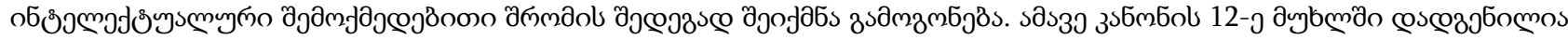

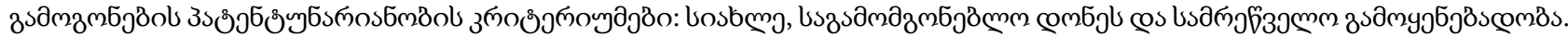

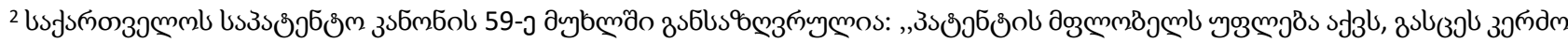

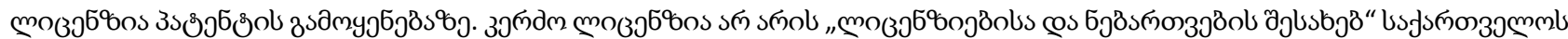

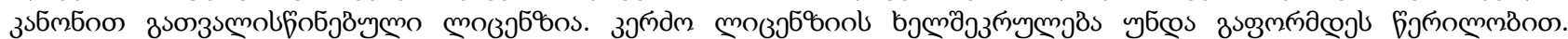

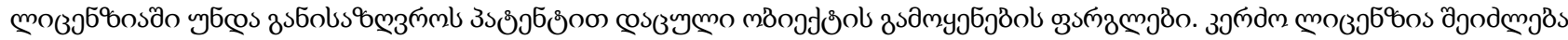

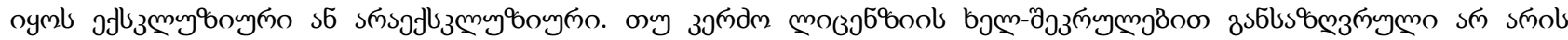

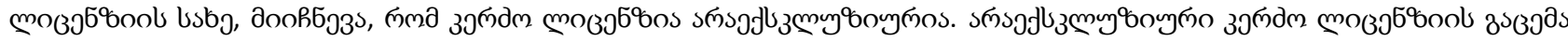

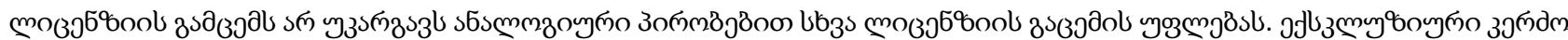

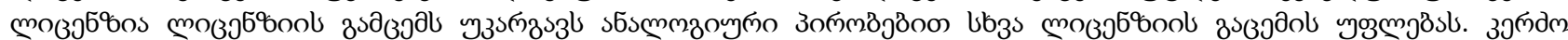

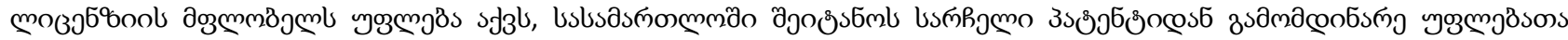

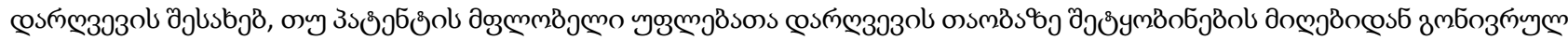

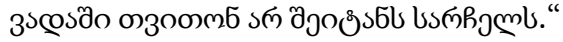




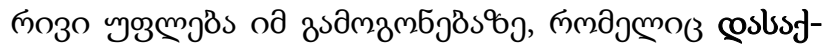

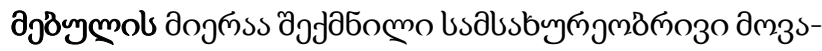

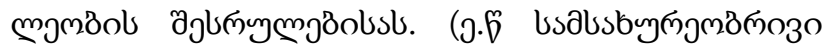

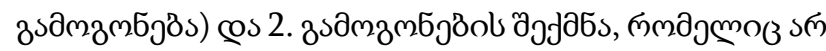

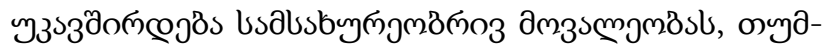

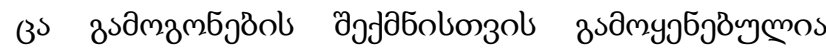

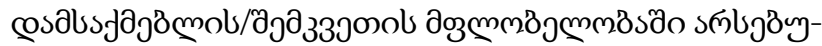

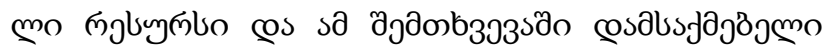

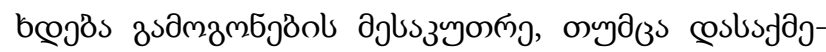

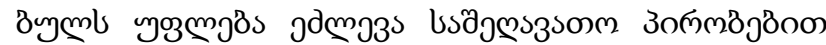

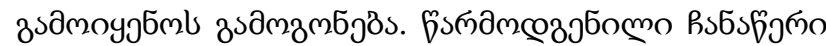

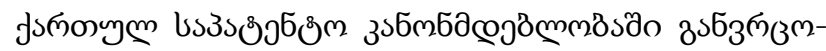

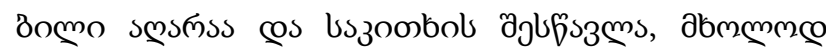

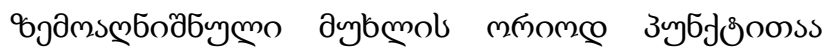

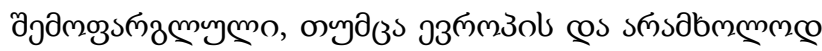

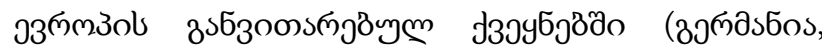

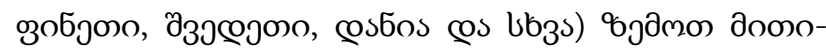

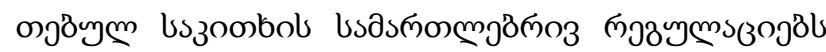

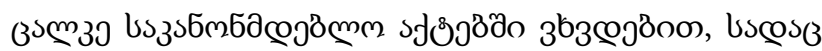

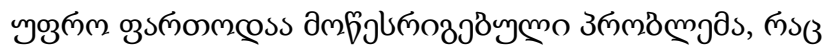

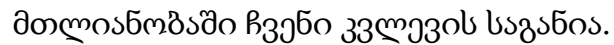

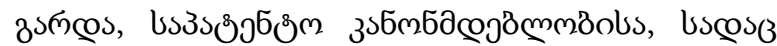

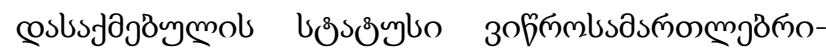

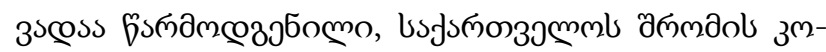

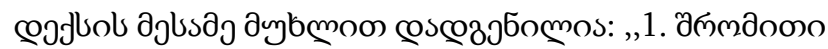

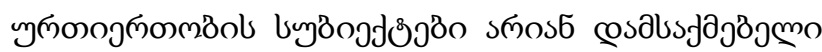

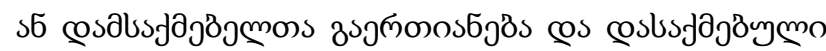

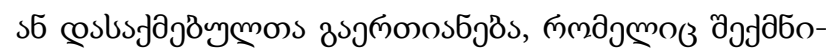

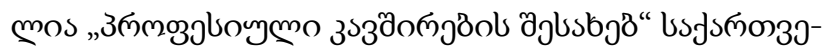

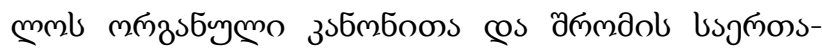

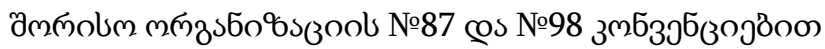

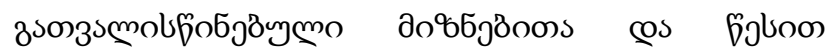

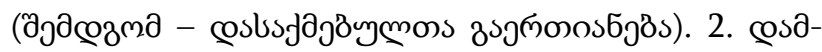

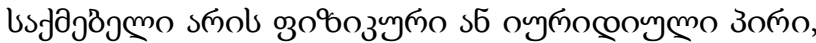

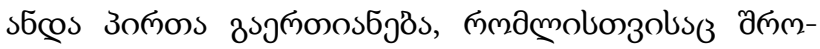

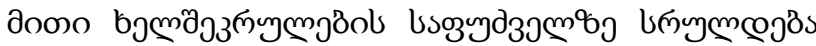

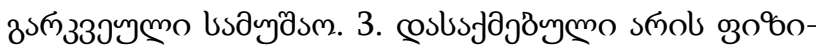

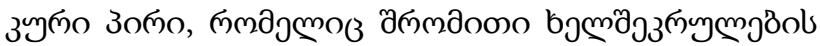

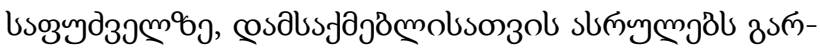
з3ээym bsaỹusmb"

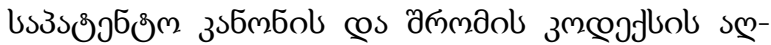

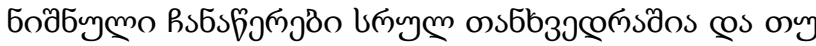

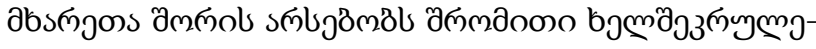

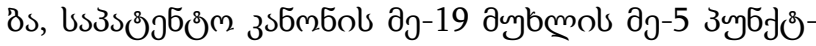

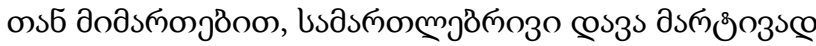

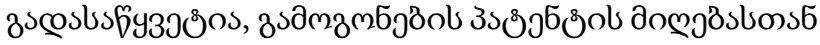

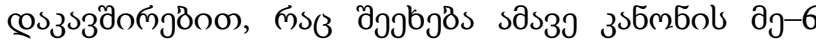

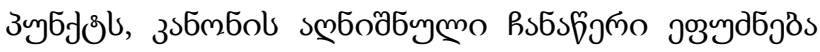

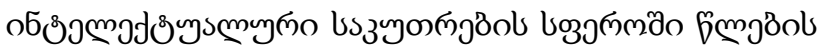

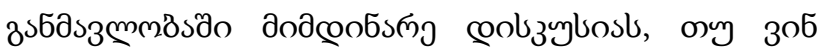

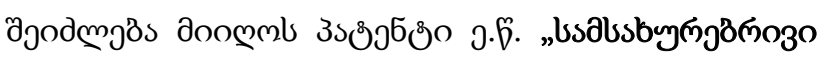

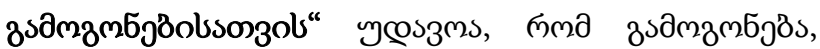

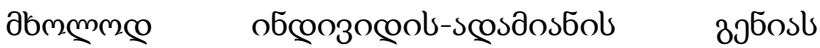

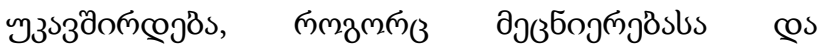

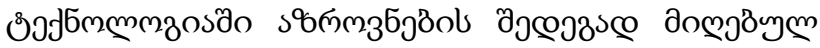

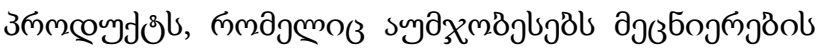

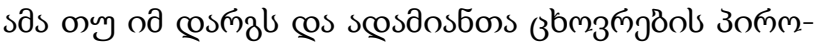

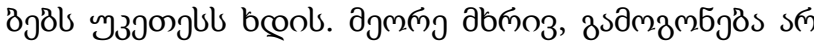

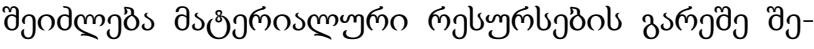

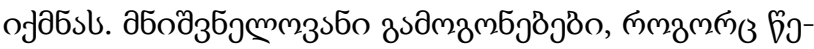

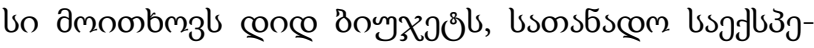

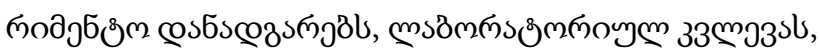

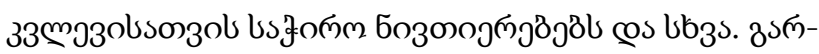

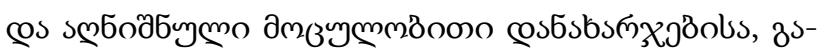

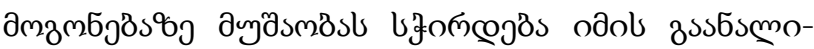

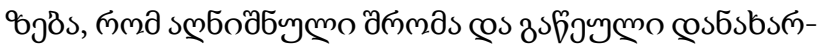




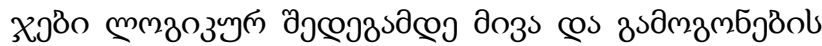

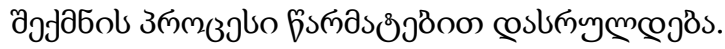

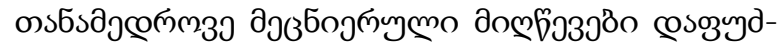

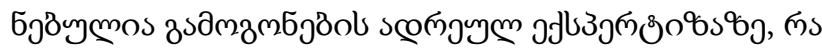

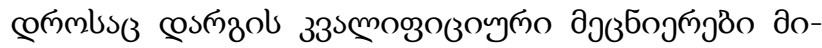

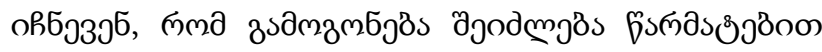
œоззопззобюуь.

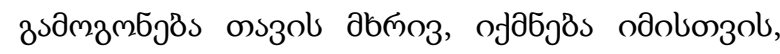

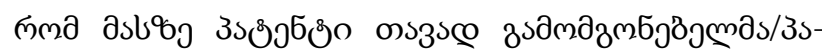

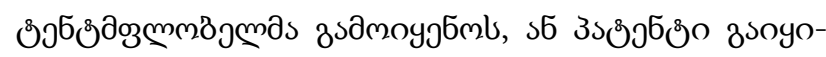

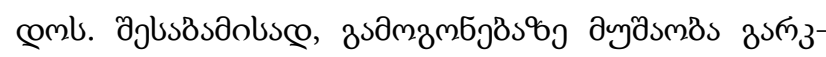

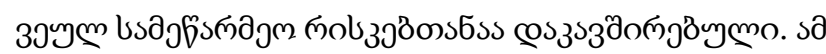

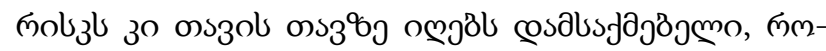

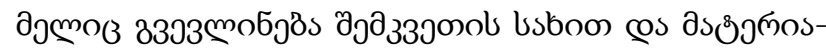

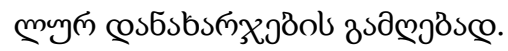

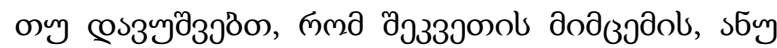

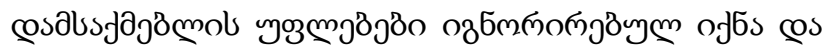

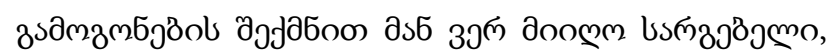

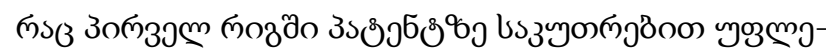

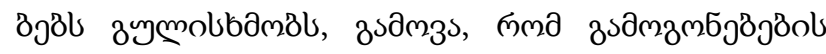

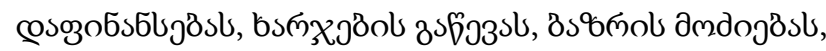

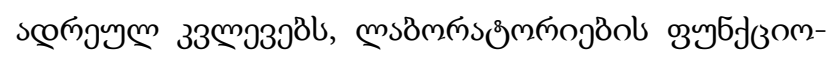

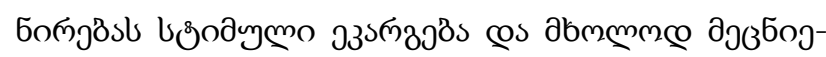

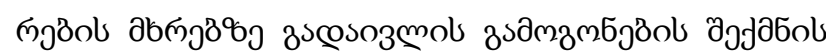

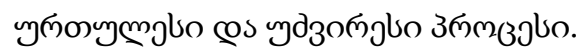

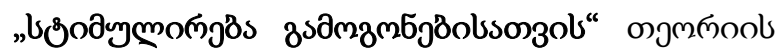

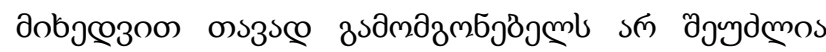

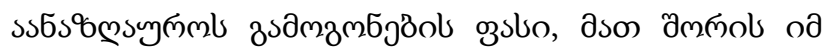

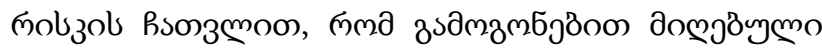

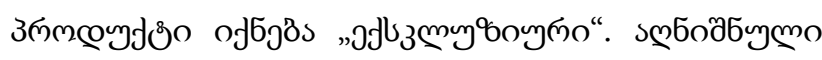

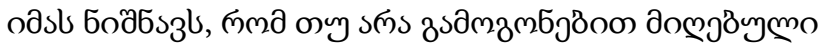

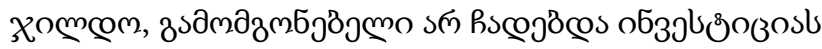

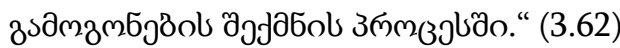

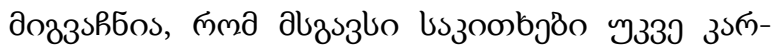

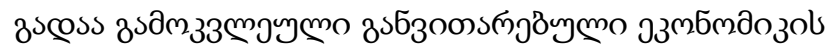

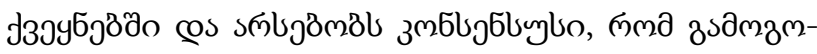

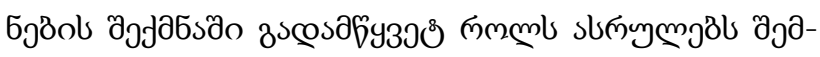

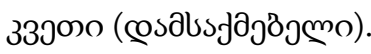

„ழsus

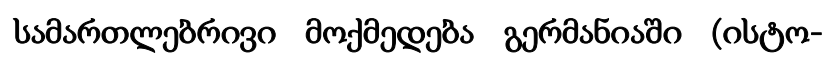

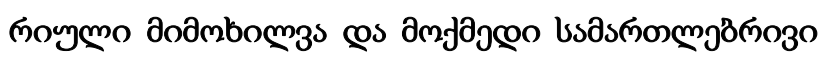

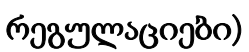

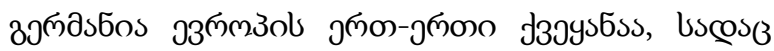

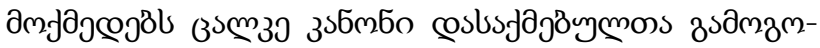

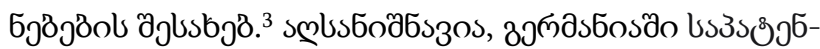

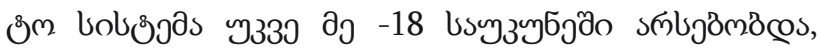

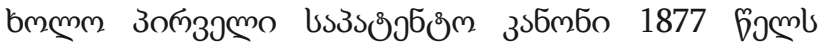

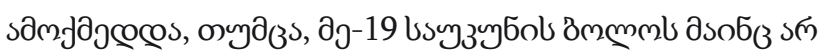

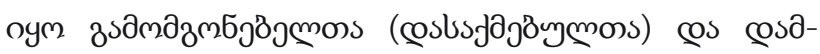

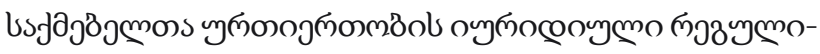

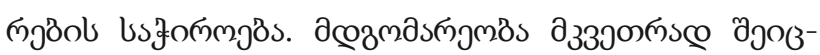

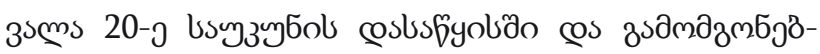

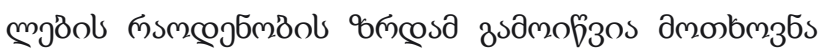

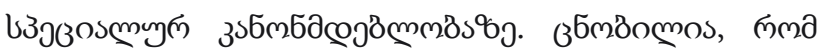

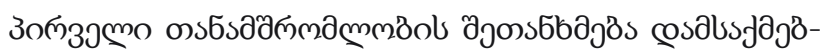

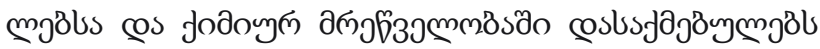

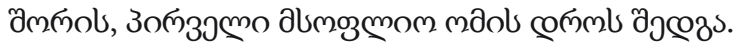

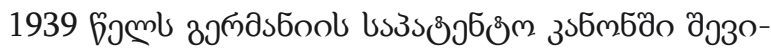

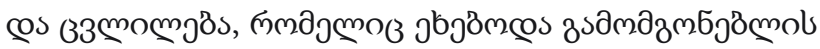

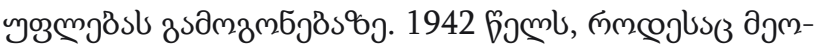

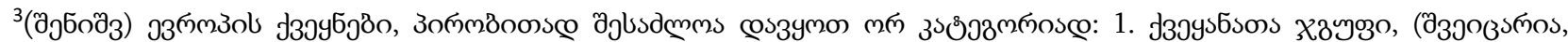

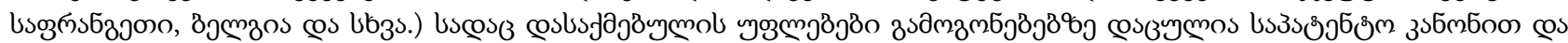

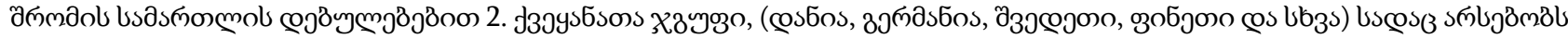

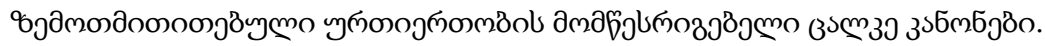




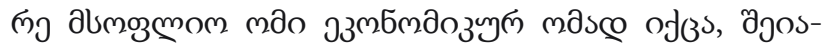

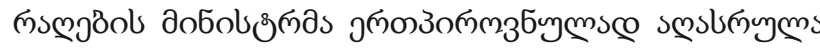

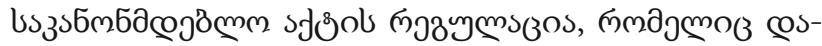

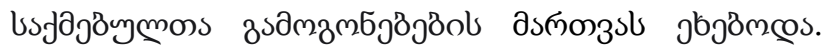
(Verordnung über die Behandlung von Erfindungen von

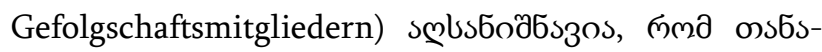

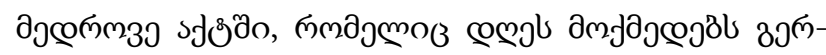

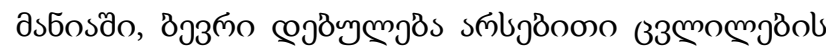

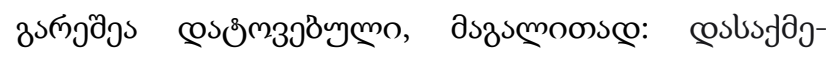

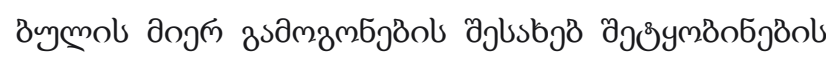

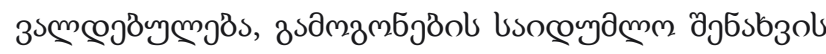

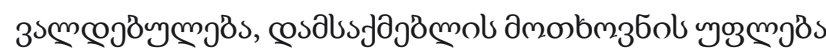

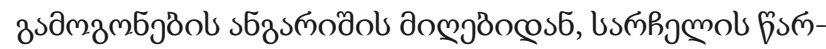

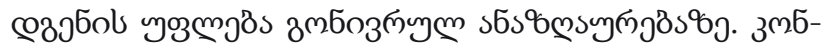

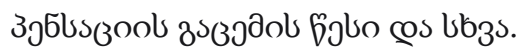

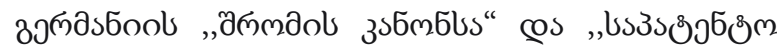

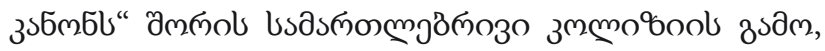

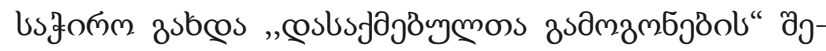

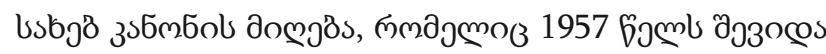

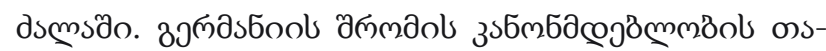

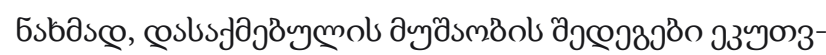
бol cosalss

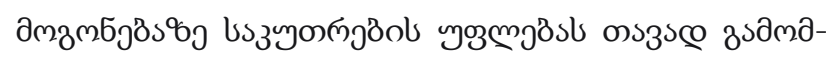

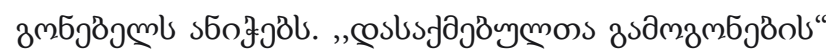

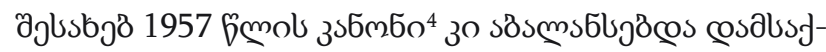

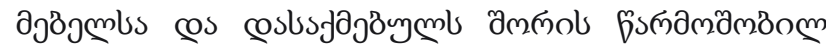

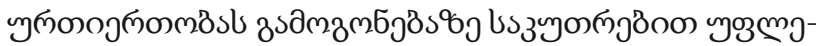

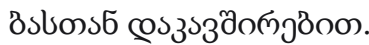

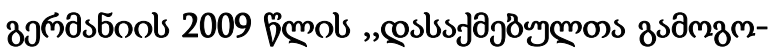

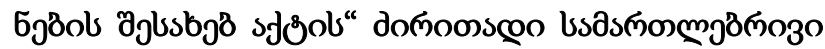

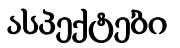

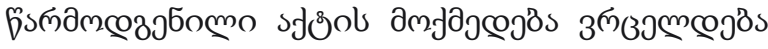

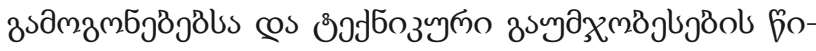

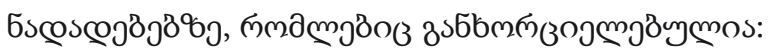

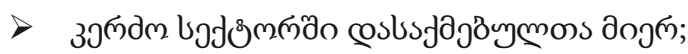

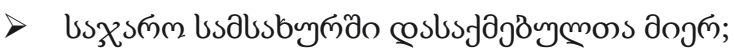

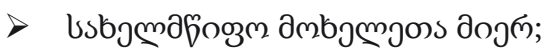

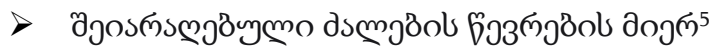

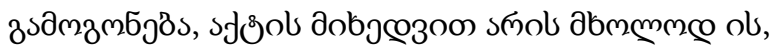

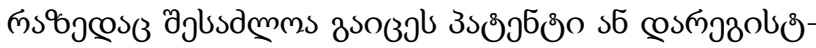

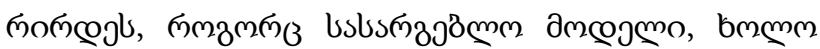

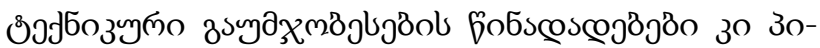

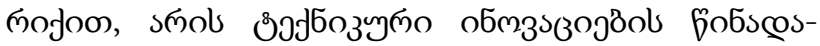

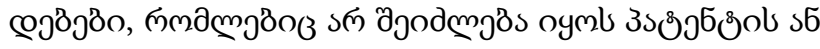

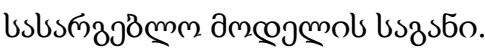

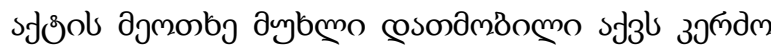

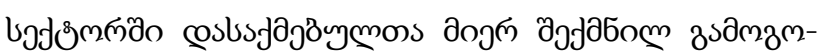

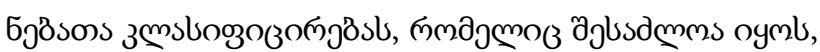

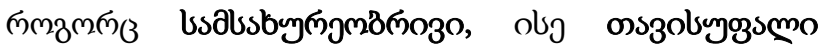
$(\text { yogstsm })^{6}$

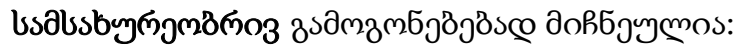

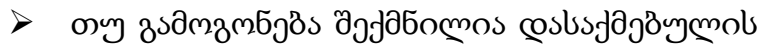

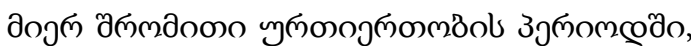

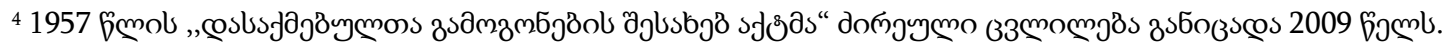

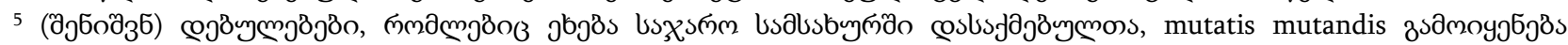

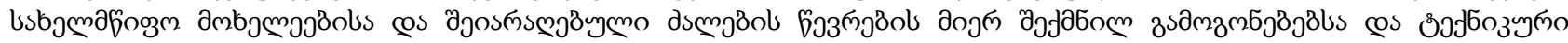

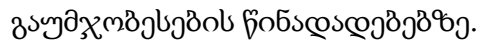

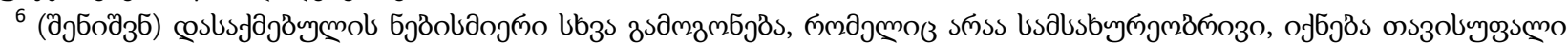

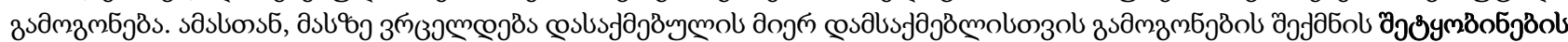

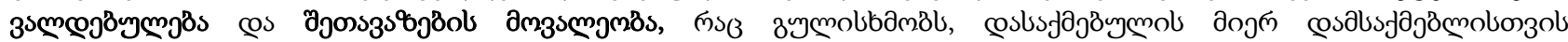

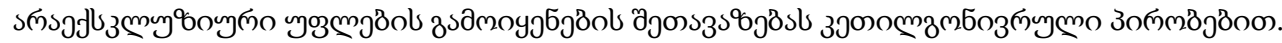




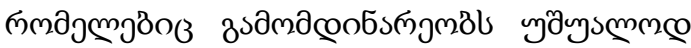

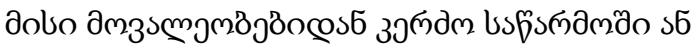

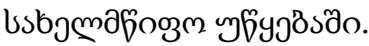

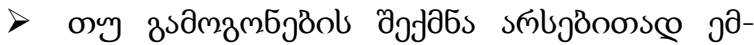

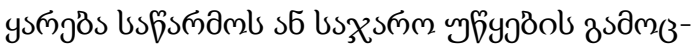

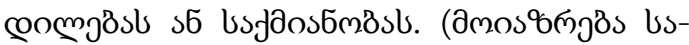

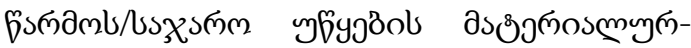

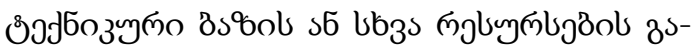

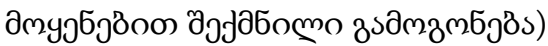

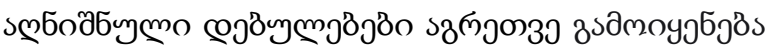

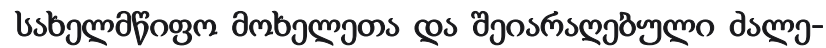

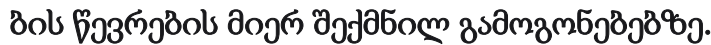

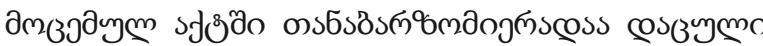

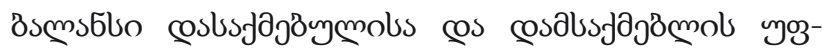

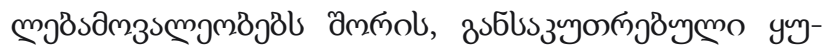

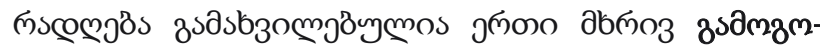

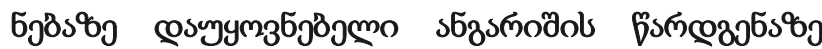

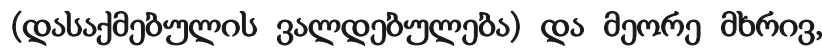

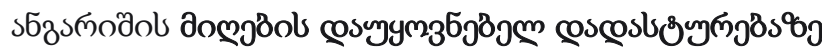
(csals

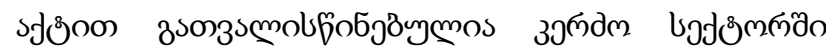

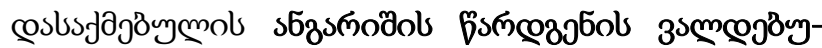

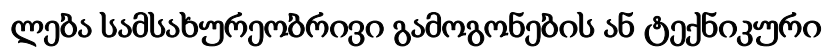

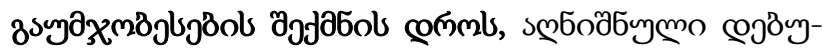

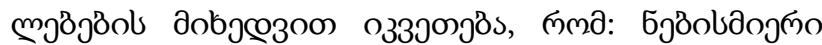

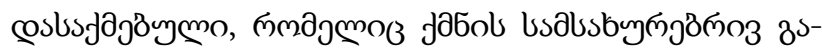

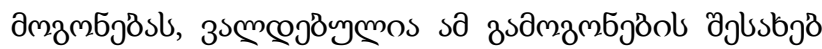

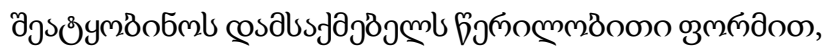

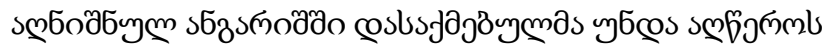

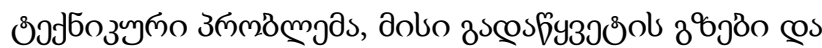

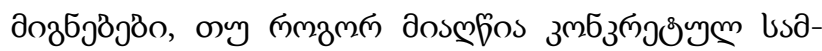

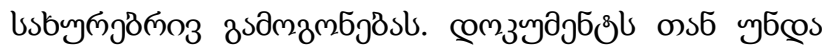

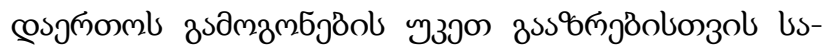

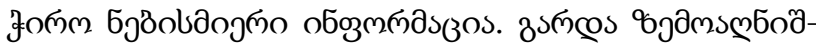

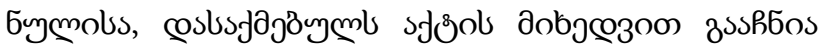

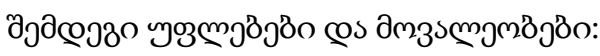

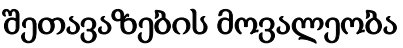

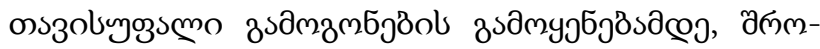

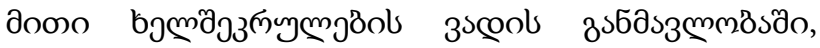

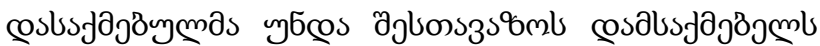

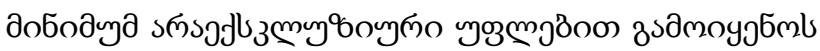

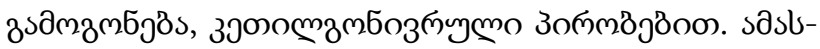

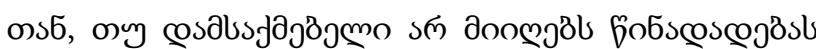

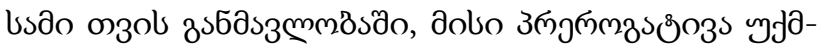
coß̉s.

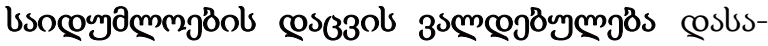

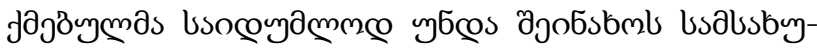

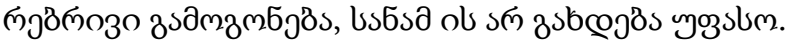

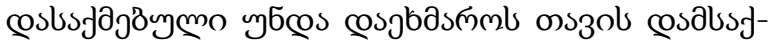

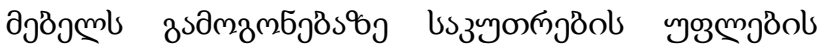

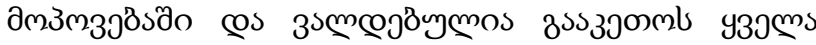

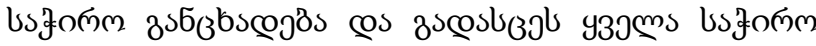

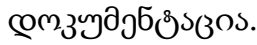

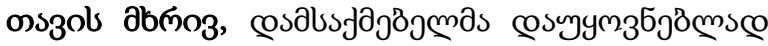

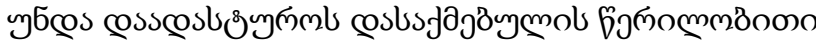

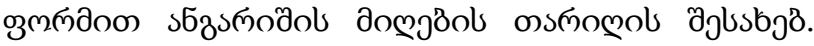

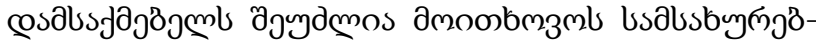

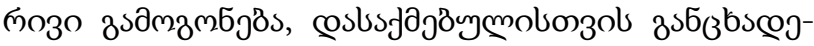

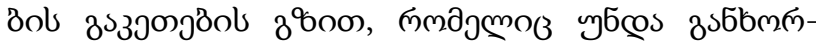

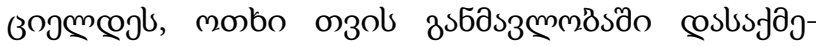

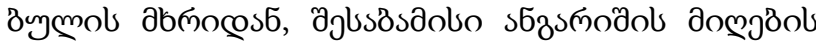

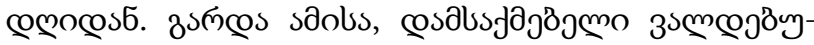

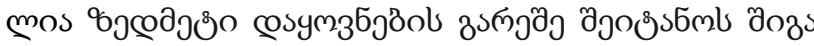

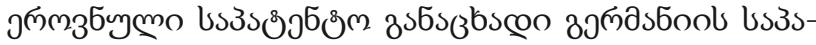

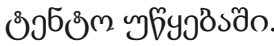




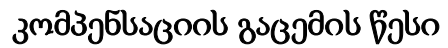

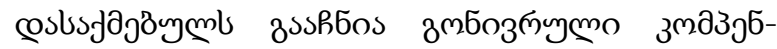

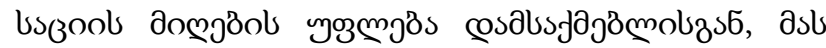

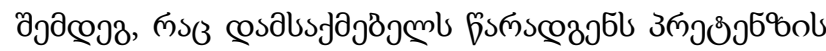

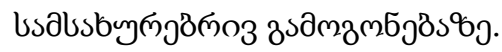

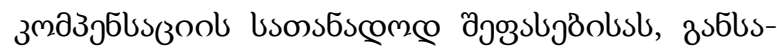

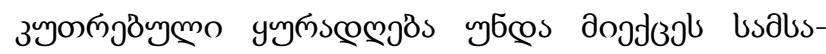

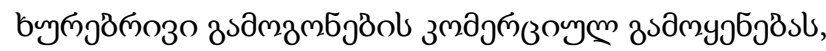

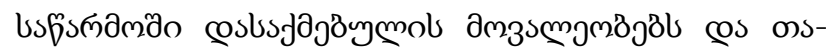

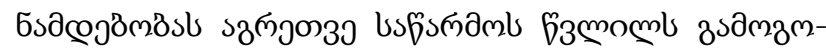

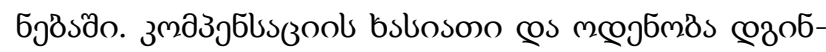
cəỏs cosals

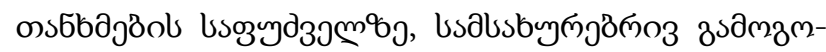

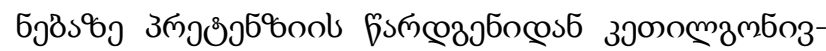

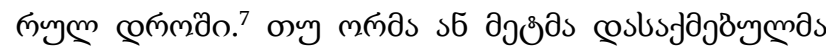

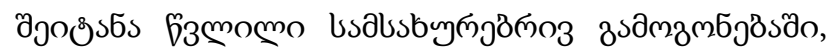

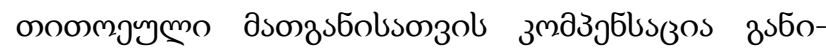

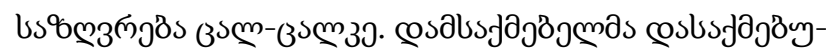

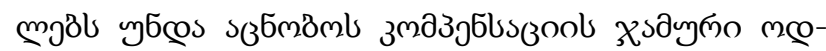

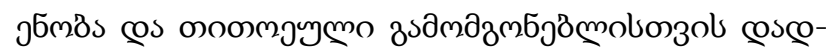
зэбомо бомпо.

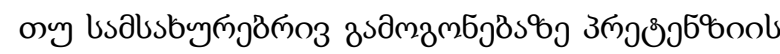

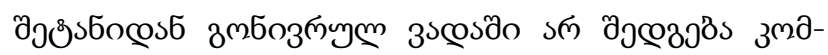

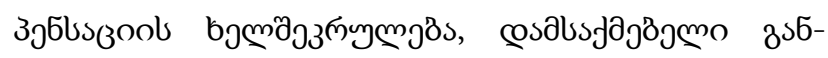

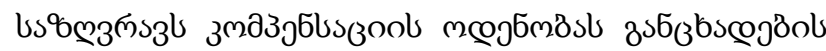

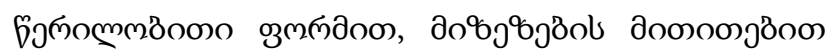

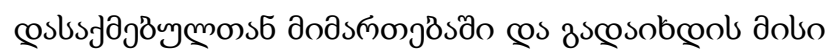

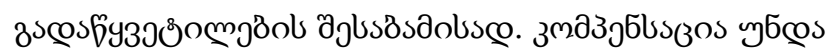

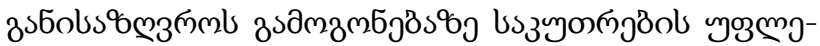

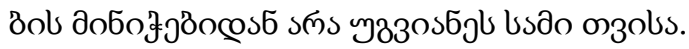

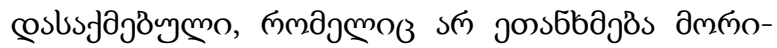

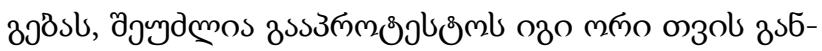

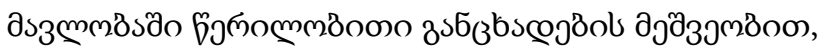

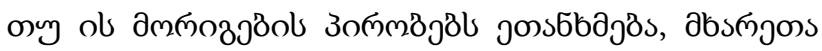

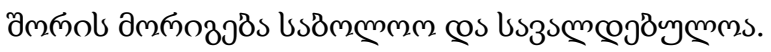

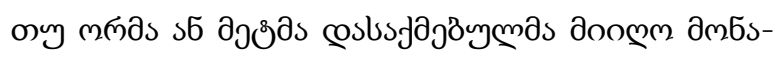

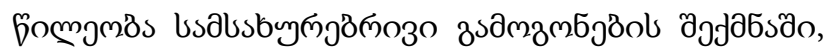

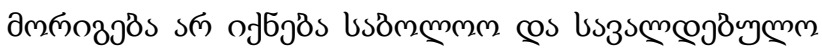

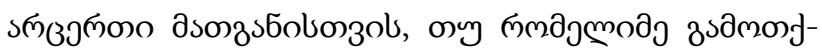

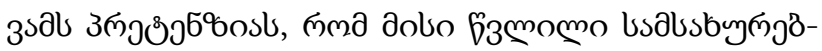

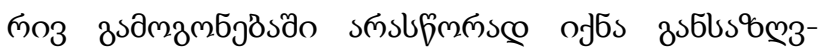

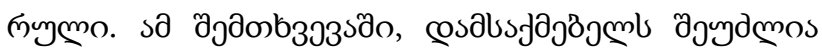

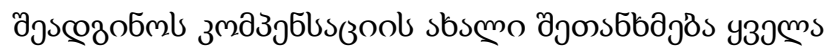
abs๘olsonzol.

cosals

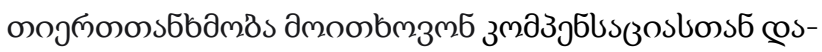

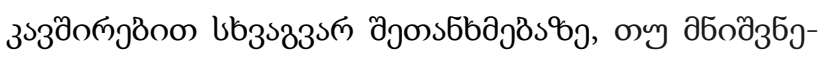

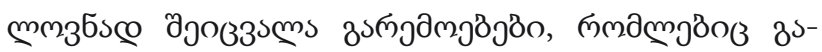

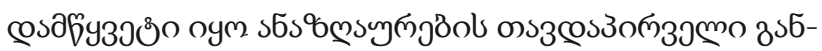
us\%мзпо

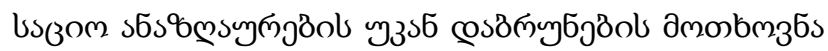

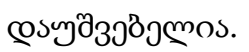

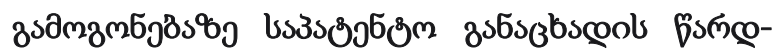

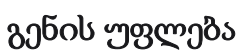

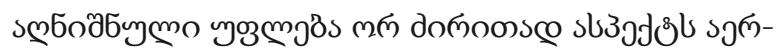
๓оs6jßl:

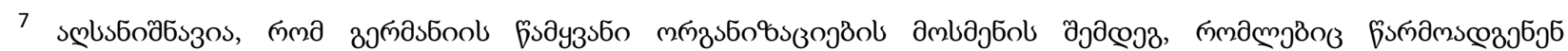

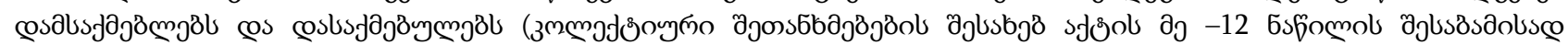

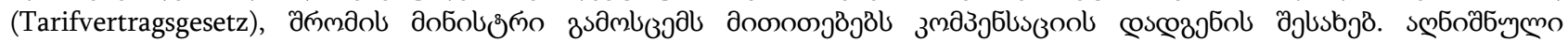

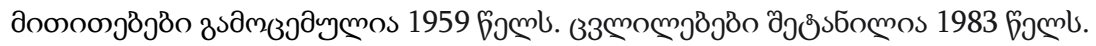




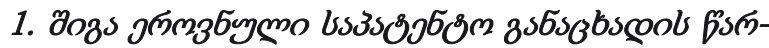

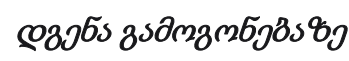

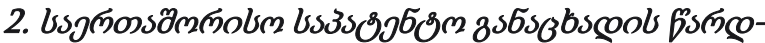

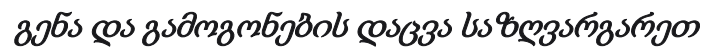

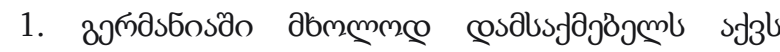

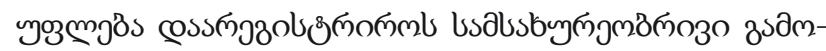

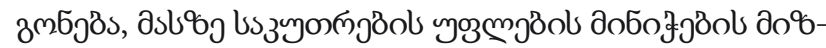

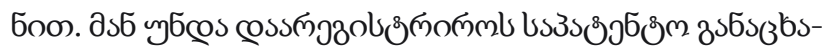

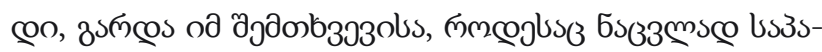

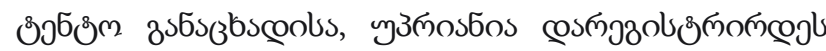

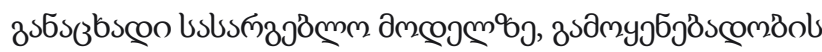

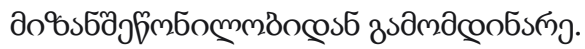

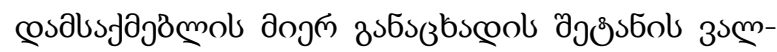

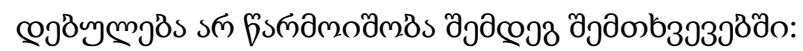

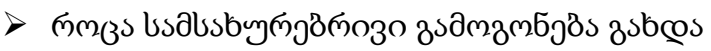
mszoluyozsmo 8

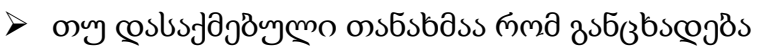

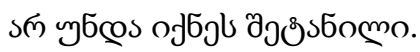

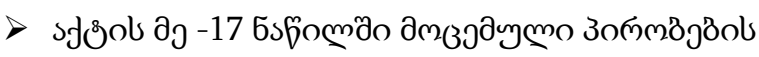

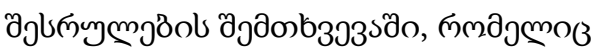

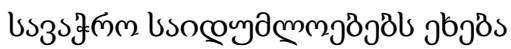

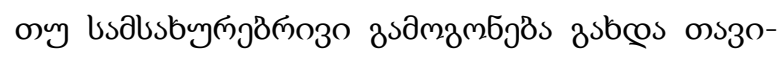

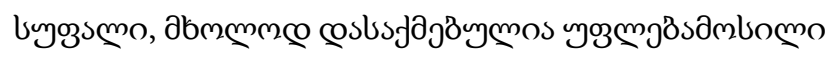

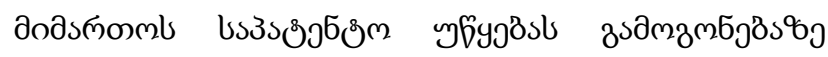

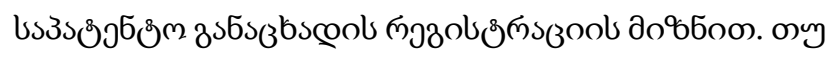
cosals

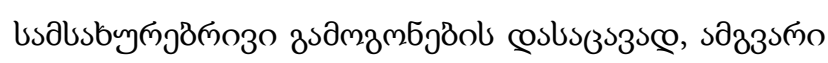

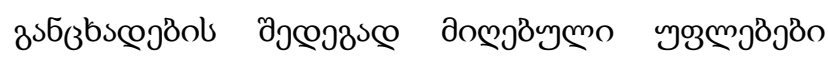

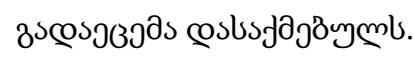

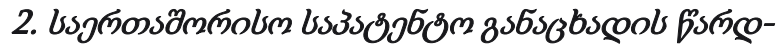

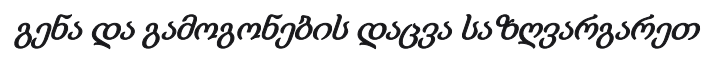

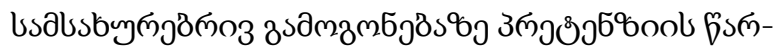

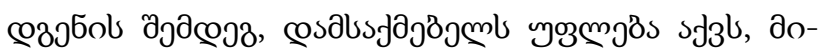

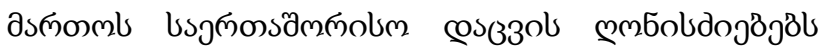

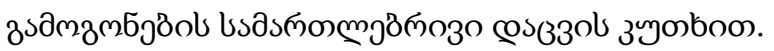

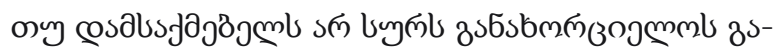
амдмб

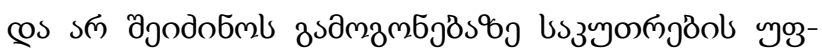

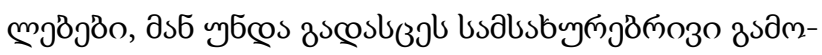

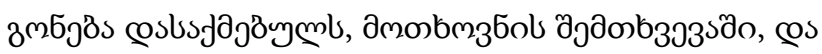

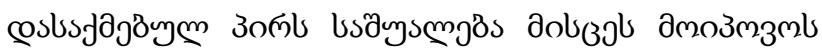

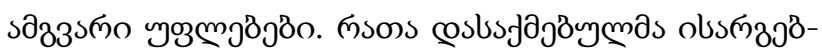

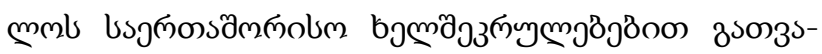

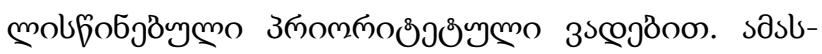

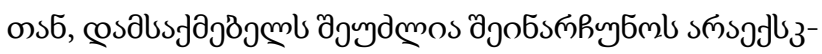

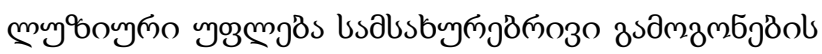

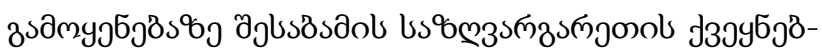

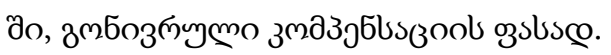

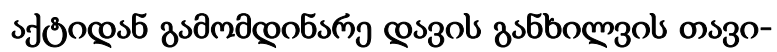

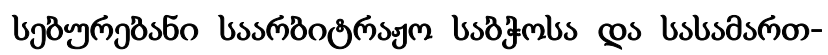
мmðัo

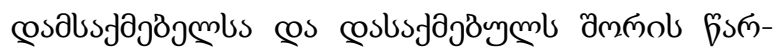

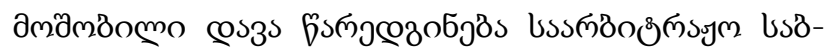

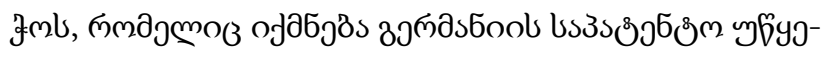

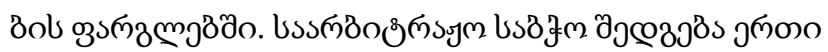

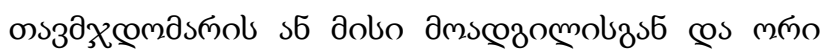

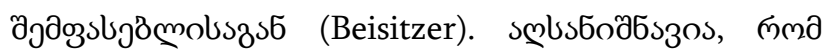

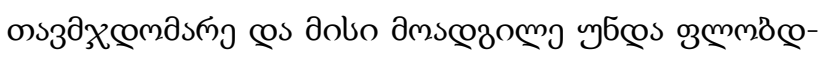

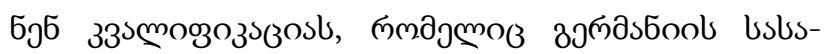

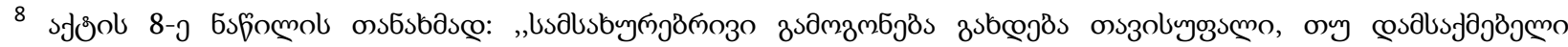

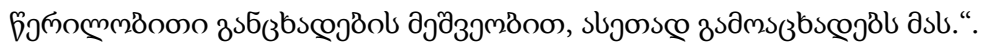

https:/wipolex.wipo.int/en/legislation/members/profile/DE
} 


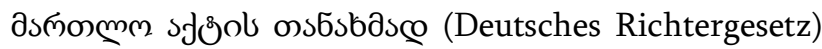

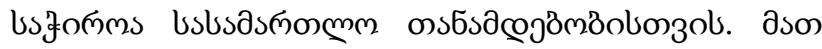

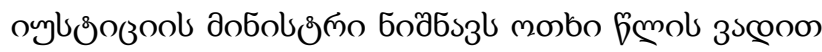
cos cosbs

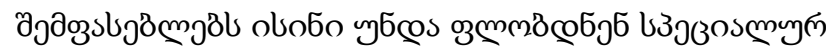

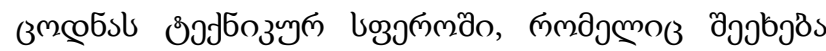

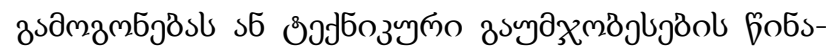

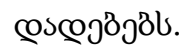

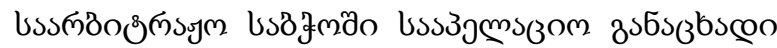

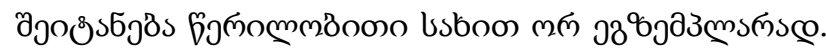

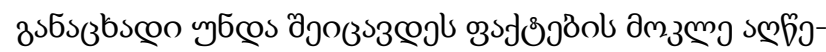

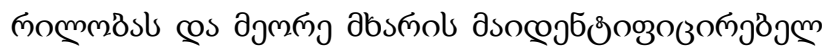

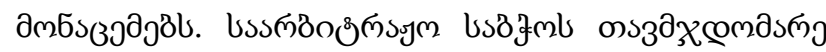

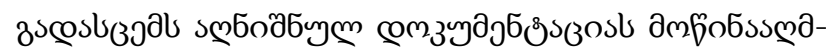

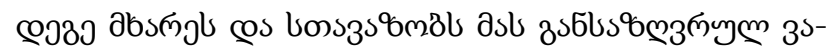

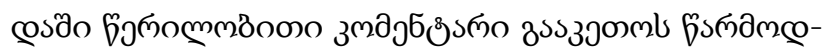

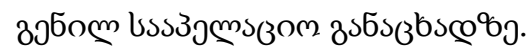

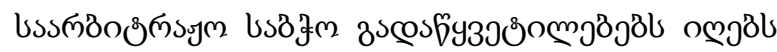

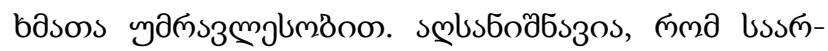

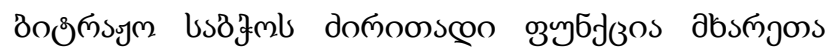

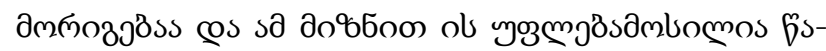

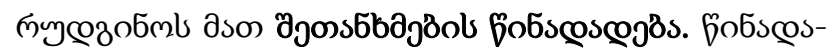

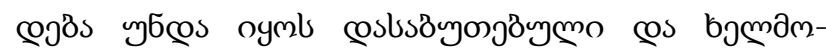

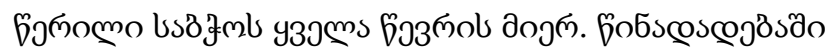

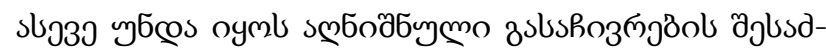

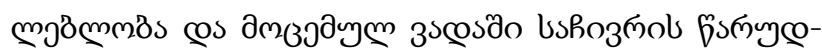

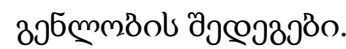

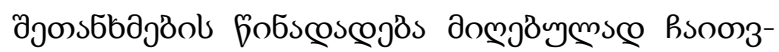

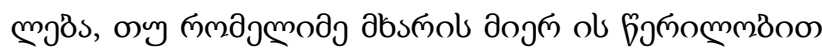

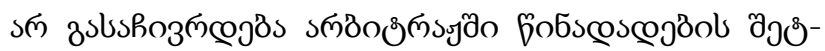

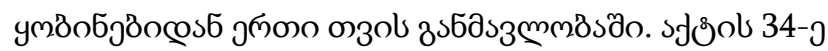

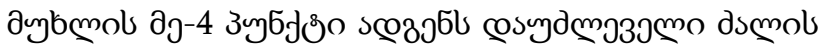

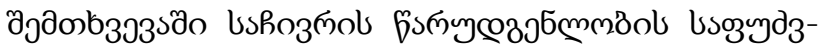

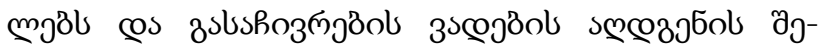

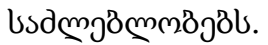

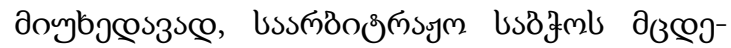

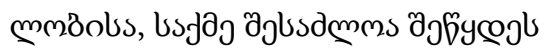

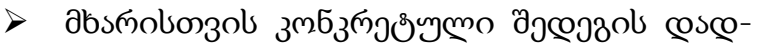
змдоl дs

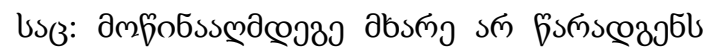

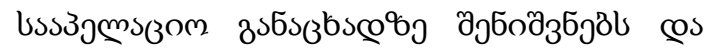
gazslugbgasts.

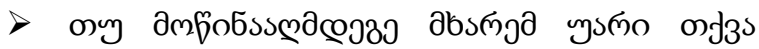

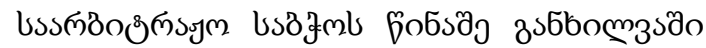

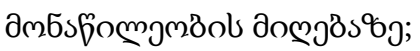

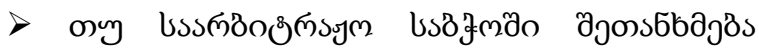

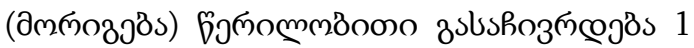
mzol zsç⿰丿丨.

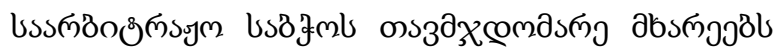

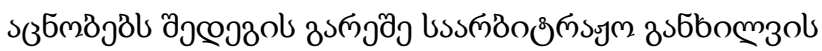

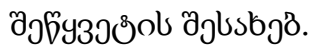

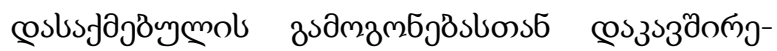

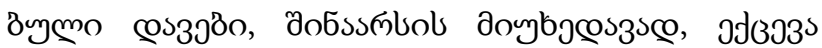

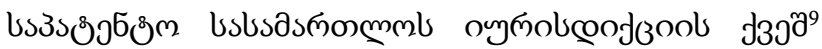

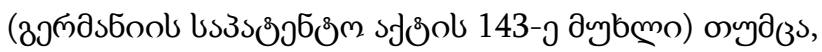

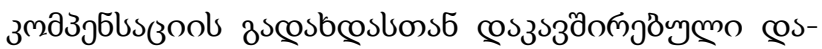

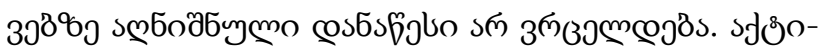

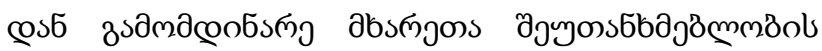

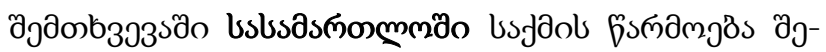

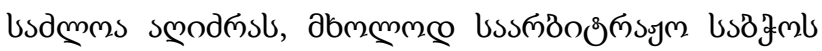

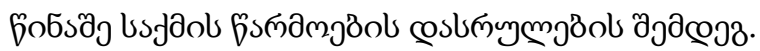

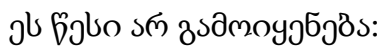

\footnotetext{
${ }^{9}$ Patentgesetz - https://wipolex.wipo.int/en/text/461309
} 


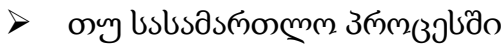

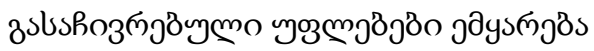

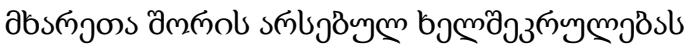

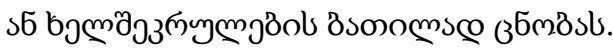

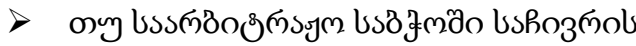

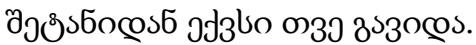

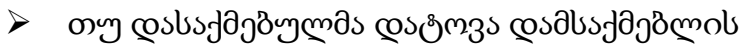
usf̧sलдам.

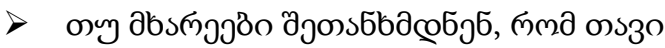

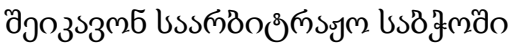

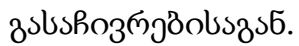

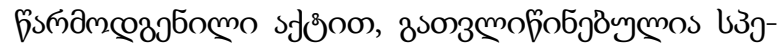

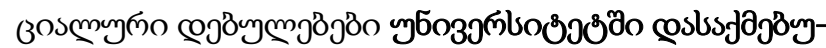

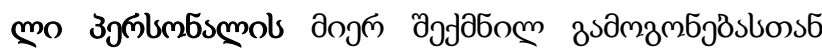

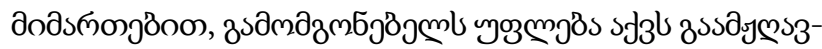

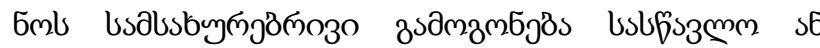

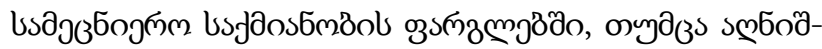

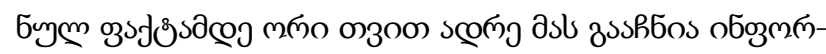

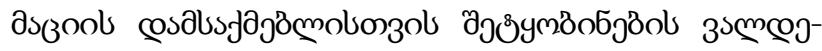

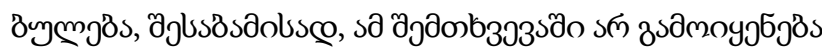

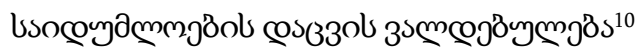

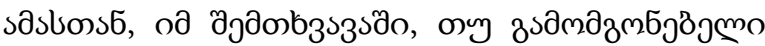

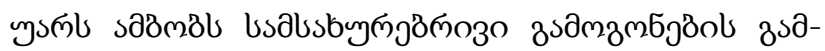

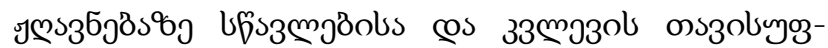

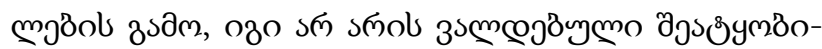

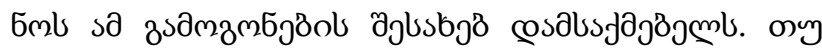

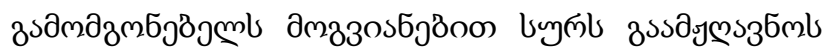

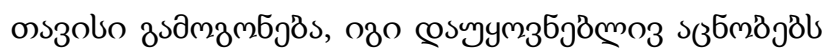

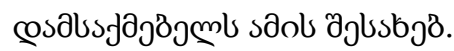

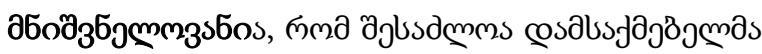

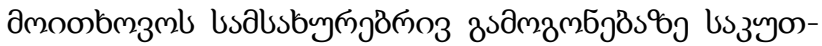

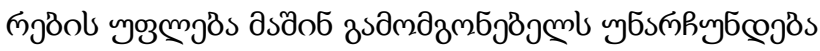
sলs

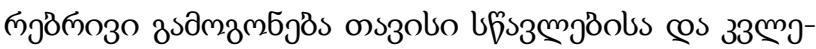

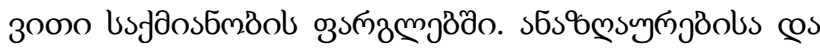

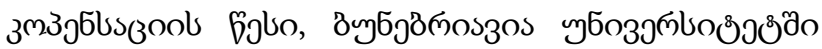

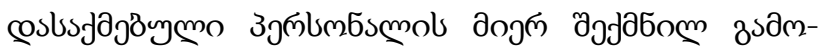

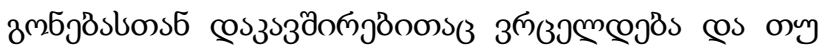

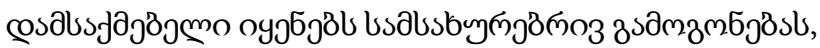

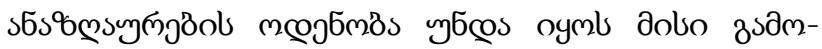

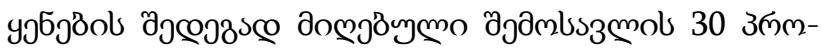

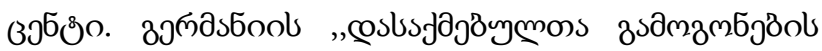

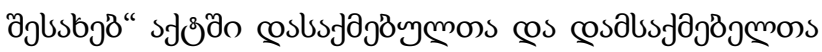

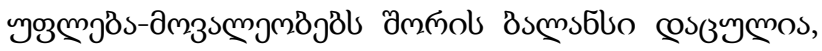

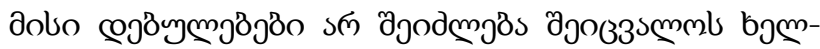

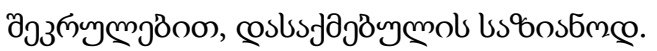

\section{coslos $336 s$}

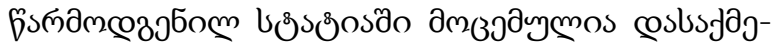

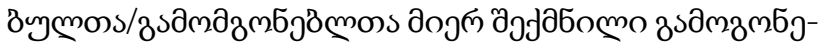

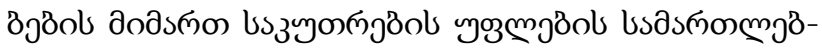

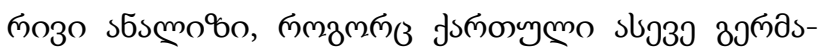

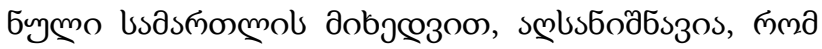

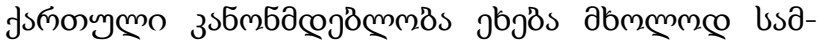

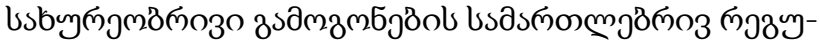

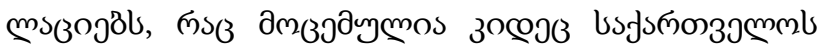

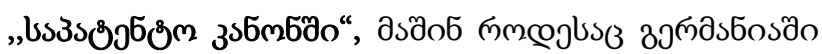

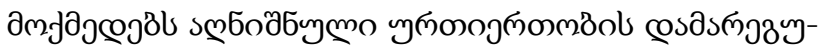
моп̆

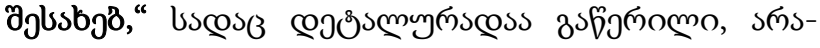

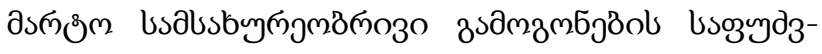

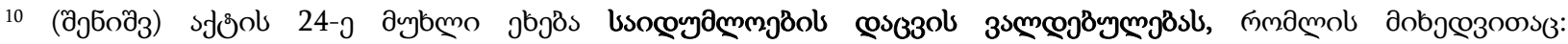

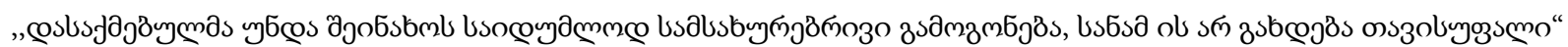




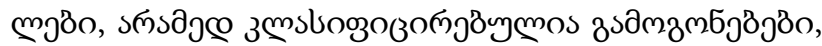

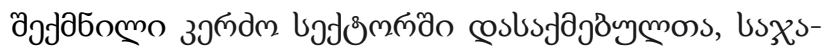

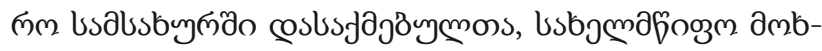

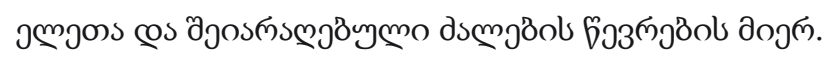

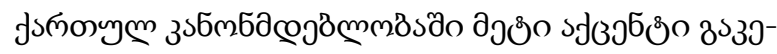

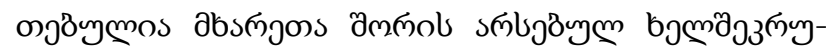

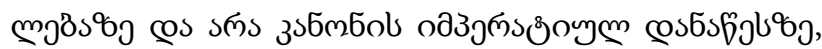

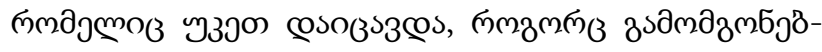

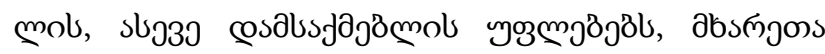

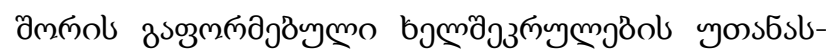

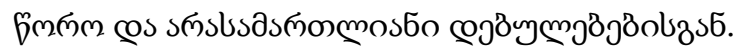

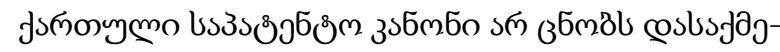

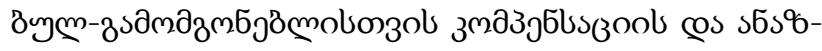

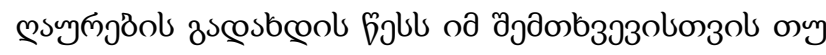

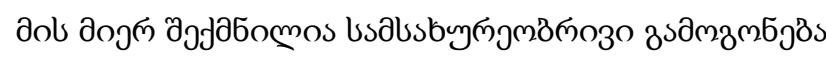

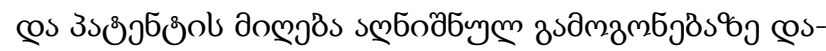

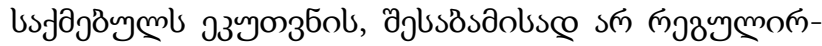

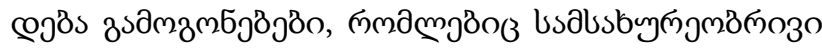

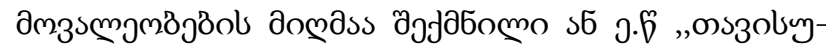

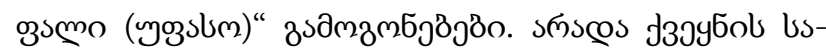

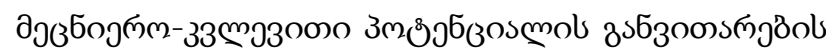

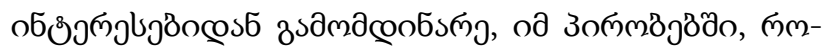

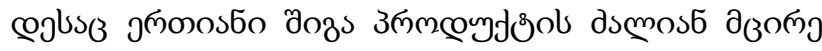

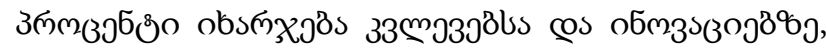

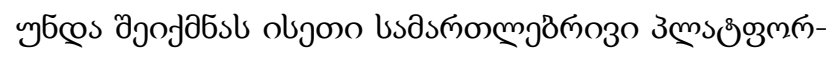

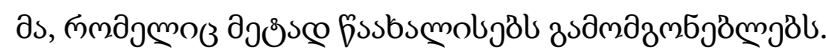

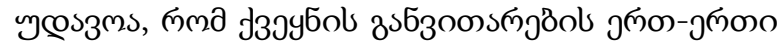

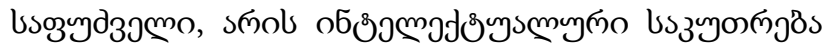

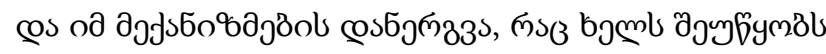

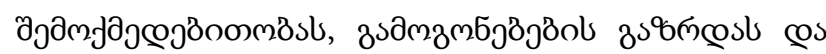

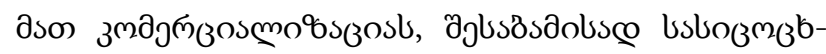

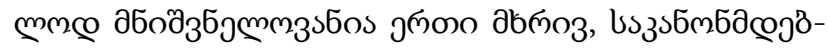

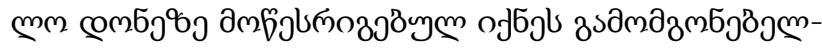

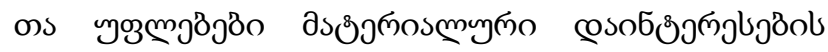

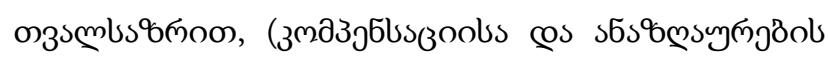

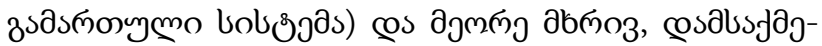

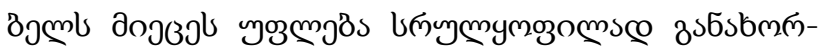

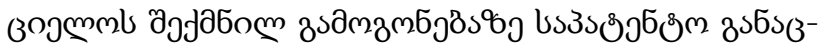

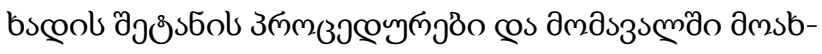

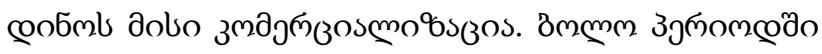

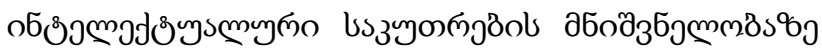

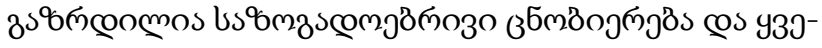

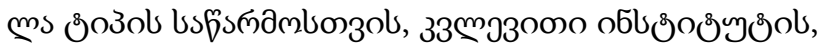

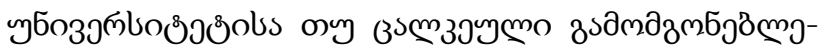

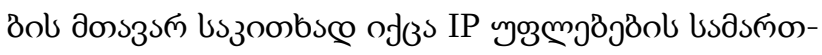

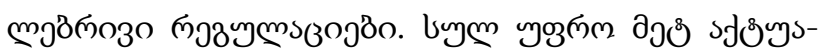

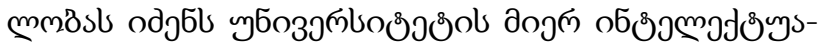

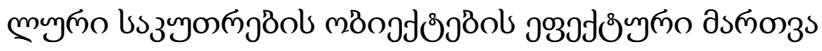

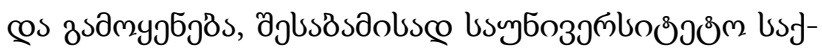

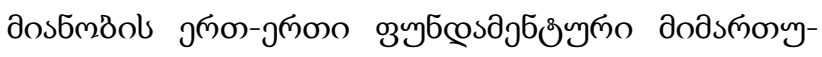

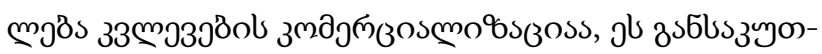

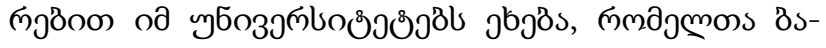

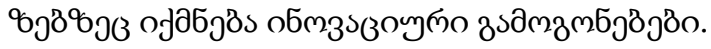

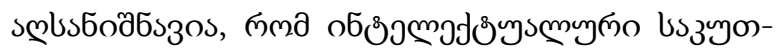

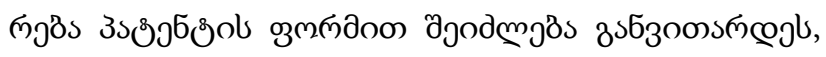

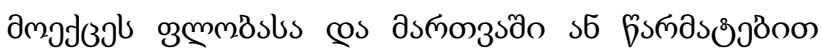

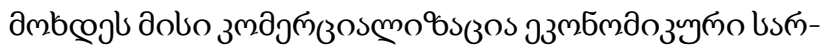

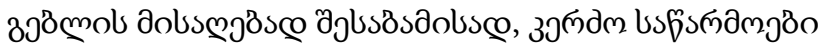

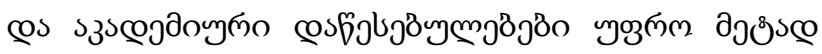

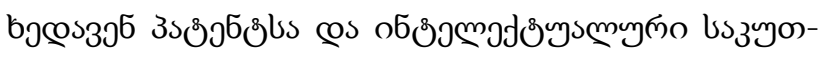

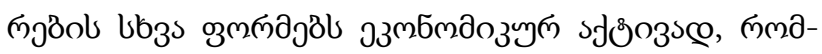

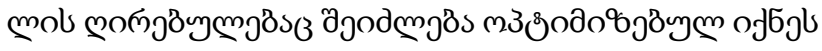

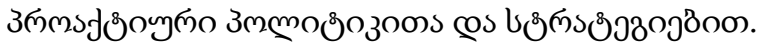

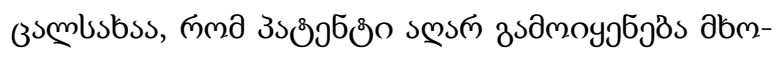

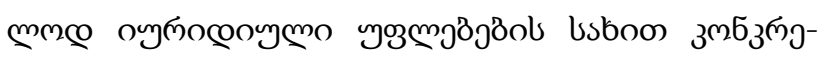

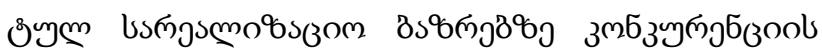

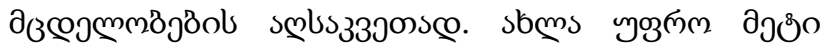
sЈ

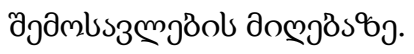




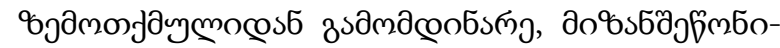

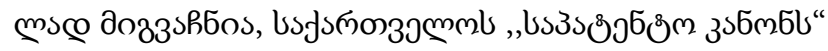

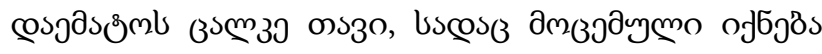

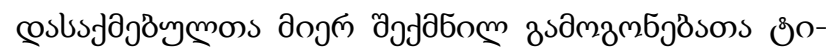

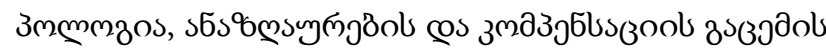

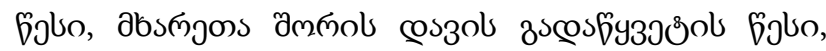

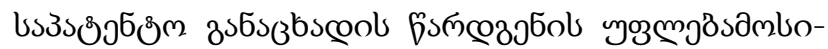

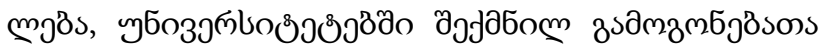

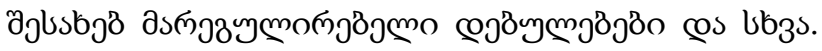

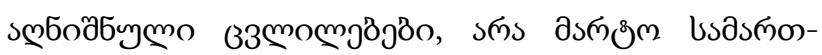

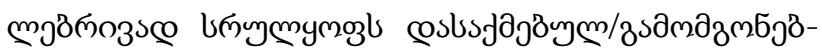

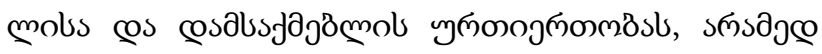

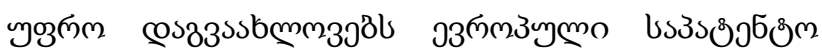

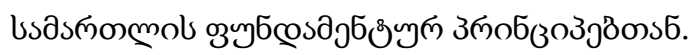

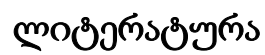

1. Jorbenadze, S. (1998). Explanatory Dictionary of Intellectual Property. (In Georgian)

2. General Course on Intellectual Law. National Intellectual Property Center of Georgia Sakpatenti. (In Georgian);

3. Chisum, D. S., Nard, A. C., Schwartz, H. F., Newman, P., Kieff, S. F. (1998). Principlies of Patent Law. New York: Foundation Press. (In English)

4. Constitution of Georgia. Retrieved from: https://matsne.gov.ge/ka/document/view/30346?publication=36 (In Georgian);

5. Patent Law of Georgia. Retrieved from: https://matsne.gov.ge/document/view/11470?publication=7 (In Georgian);

6. Organic Law of Georgia Labour Code of Georgia. Retrieved from: https://matsne.gov.ge/en/document/view/1155567?impose=parallelEn\&fullscreen=1\&publication=18 (In Georgian);

7. German Employee Inventions Act. (2009). Retrieved from: https://wipolex.wipo.int/en/legislation/details/10005 (In German)

8. Patent Act. (2017). Retrieved from: https://wipolex.wipo.int/en/legislation/details/17611 (In German);

9. Association Agreement between Georgia, on the one hand, and the European Union, the European Atomic Energy Community, and their Member States, on the other. (2014). Retrieved from: https://matsne.gov.ge/document/view/2496959?publication=0 (In Georgian);

10. Tretton, G. (2002). Intellectual Property in Europe. (In English);

11. Gurgenidze, M., Urtmelidze, T. (2021). Aspects of Compulsory Licensing in Patent Law. Tbilisi: Works of GTU, 1(519). (In Georgian).

12. World Intellectual Property Organization. Retrieved from: https://www.wipo.int/wipolex/en/index.html

13. Sakpatenti. Retrieved from: https://www.sakpatenti.gov.ge/ka/ 
UDC 347.21.3

SCOPUS CODE 3301

https://doi.org/10.36073/1512-0996-2021-3-152-167

The Right of the Employee to an Invention Created in the Process of Labor Relations. (In Accordance With the Georgian - German Patent Legislation)

\author{
Miranda Gurgenidze Department of Private Law, Georgian Technical University, Georgia, 0160, Tbilisi, 77 \\ M. Kostava str. \\ E-mail: mirgurgenidze@gmail.com \\ Tamaz Urtmelidze Department of Private Law, Georgian Technical University, Georgia, 0160, Tbilisi, 77 \\ M. Kostava str. \\ E-mail: t.urtmelidze@gmail.com
}

\title{
Reviewers:
}

Ts. Gloveli, Professor, Faculty of Law and International Relations, GTU

E-mail: gloveli99@mail.ru

N. Kharitonashvili, Associate Professor, Guram Tavartkiladze University

E-mail: nkharitonashvili@gmail.com

Abstract. Creative activity, which ends with the creation of intellectual property objects, are mostly carried out by individuals employed in various private sectors or scientists working in higher education/research institutions.

Therefore, the question who is the owner of the intellectual property object (invention), employee/inventor, whose direct participation with and usage of intellectual labor, the object was created by, or the employer, whose material technical base, experience and the other resources were used to create the invention, does not lose relevance.

Georgia belongs to the continental, i.e. Romano-Germanic legal system. Modern Georgian intellectual property law has undergone a very interesting path of development since the restoration of independence. It should be noted that Georgia is the first country from the former Soviet republics to establish a national patent agency in 1992 $(12,246)$.

In this article, the authors focus on the basic regulations of Georgian and German patent law that regulate the ownership of an invention created by employees. As it is known, in Georgia the issue is resolved by the „Patent Law“, while in Germany, in addition to the patent law, there is an „Employee Inventions Act“.

The scientific article consists of an introduction, a main part and a conclusion. The introduction presents the urgency of the legal problem. The main part, on the one hand, discusses the legal status of inventions created by employees, gives the relationship between patent law and labor law on this issue (on the example of Georgian legislation) and, on the other hand, the authors analyze the German ,Employee Inventions Act“, which we find a 
detailed arrangement of an issue of interest to us in. The law is structured in such a way that the balance between the interests of the employee and the employer is maximally maintained, the rule of compensation is provided, a distinction is made between service and free inventions, and ways of resolving disputes between the parties are provided. The legal basis for arbitration is in the foreground. There is also a court of law under the jurisdiction of which these disputes are considered.

Key words: compensation; employee; employer; inventor; patent law; labor law; service invention.

UDC 347.21.3

SCOPUS CODE 3301

https://doi.org/10.36073/1512-0996-2021-3-152-167

\section{Право работника на изобретение, созданное в процессе трудовых отношений (в соответствии с грузино-германской патентным законодательством)}

Миранда Гургенидзе Департамент частного права, Грузинский технический университет, Грузия, 0160, Тбилиси, М. Костава 77

E-mail: mirgurgenidze@gmail.com

Тамаз Уртмелидзе Департамент частного права, Грузинский технический университет, Грузия, 0160, Тбилиси, М. Костава 77

E-mail: t.urtmelidze@gmail.com

\section{Рецензенты:}

Ц. Гловели, профессор факультета права и международных отношений ГТУ

E-mail: gloveli99@mail.ru

Н. Харитонашвили, ассоциированный профессор Университета им. Гурама Таварткиладзе

E-mail: nkharitonashvili@gmail.com

Аннотация. Творческая деятельность, которая заканчивается созданием объектов интеллектуальной собственности, в основном осуществляется лицами, работающими в различных частных секторах или учеными-сотрудниками, работающими в высших учебных/исследовательских учреждениях.

Исходя из этого, не теряет актуальности вопрос о том, кто же является владельцем объекта интеллектуальной собственности (изобретения), работник/изобретатель, при непосредственном участии и использовании 
интеллектуального труда, с помощью которого создан объект, или работодатель, материально-техническая база, опыт и другие ресурсы которого были использованы для воплощения изобретения в жизнь.

Грузия принадлежит к континентальной, то есть романо-германской правовой системе. Современное грузинское право интеллектуальной собственности прошло очень интересный путь развития со дня восстановления независимости. Одним из приоритетных направлений Грузия определила создание национальной системы защиты интеллектуальной собственности, что нашло отражение в конституции страны и соответствующих законодательных актах. Следует отметить, что Грузия первая страна из бывших советских республик, создавшая Национальное патентное ведомство в 1992 году (12.246).

В представленной статье авторы основное внимание уделяют основным регуляциям грузинского и германского патентного права, которые регулируют право собственности на изобретение, созданное работниками. Как известно, в Грузии указанный вопрос решается «Патентным законом», в то время как в Германии, помимо патентного закона, действует акт «Об изобретениях работников».

Научная статья состоит из введения, основной части и заключения. Во введении представлена актуальность правовой проблемы, в основной части, с одной стороны, рассматривается правовой статус изобретений, созданных работниками, раскрывается взаимоотношение между патентным и трудовым правом по данному вопросу (на примере законодательства Грузии), и с другой стороны - авторами проанализирован акт Германии «Об изобретениях работников», в котором мы находим детальное упорядочение интересующего нас вопроса.

Указанный закон структурирован таким образом, что максимально соблюден баланс между интересами работника и работодателя, обеспечен порядок выдачи компенсации, проводится различие между служебными и свободными изобретениями, предусмотрены пути разрешения спора между сторонами. На первый план выдвигается правовая основа арбитражного урегулирования. Также упомянут суд, который рассмотривает указанные споры.

Ключевые слова: изобретатель; компенсация; патентное право; работник; работодатель; служебное изобретение; трудовое право.

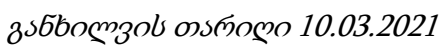 \\ дудmbз

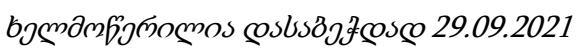

